\title{
Mathematical Modeling of Landslide Slope Dynamics and Sustainable Development of Territories of Asian Russia
}

\section{Valery S. Khoroshilov}

Siberian State University of Geosystems and Technologies: Sibirskij gosudarstvennyj universitet geosistem i tehnologij

Alexander P. Karpik

Siberian State University of Geosystems and Technologies: Sibirskij gosudarstvennyj universitet geosistem i tehnologij

Igor A. Musikhin ( $\nabla$ i.a.musikhin_vr@ssga.ru )

Siberian State University of Geosystems and Technologies: Sibirskij gosudarstvennyj universitet geosistem i tehnologij https://orcid.org/0000-0002-6595-1400

\section{Research Article}

Keywords: landslide slope, geodetic observation, mathematical modeling, prediction model, solver, spatial expert system

Posted Date: October 25th, 2021

DOl: https://doi.org/10.21203/rs.3.rs-872336/v1

License: (c) (i) This work is licensed under a Creative Commons Attribution 4.0 International License. Read Full License 


\title{
Mathematical Modeling of Landslide Slope Dynamics and Sustainable Development of
}

\section{Territories of Asian Russia}

\author{
Valery S. Khoroshilov ${ }^{\mathrm{a} 1}$, Alexander P. Karpik ${ }^{\mathrm{a} 2}$, Igor A. Musikhin ${ }^{\text {b3* }}$ \\ ${ }^{a}$ Siberian State University of Geosystems and Technologies, Department of Space and Physical Geodesy, Novosibirsk, \\ Russia;
}

${ }^{b}$ Siberian State University of Geosystems and Technologies, Department of Photogrammetry and Remote Sensing, Novosibirsk, Russia

*Siberian State University of Geosystems and Technologies, 10, Plakhotnogo str., Novosibirsk, 630108, Russia, i.a.musikhin_vr@ssga.ru

${ }^{1}$ orcid.org/0000-0001-7246-1453

2 orcid.org/0000-0001-6657-2069

${ }^{3}$ orcid.org/0000-0002-6595-1400

\begin{abstract}
The possibilities of applying the results of modeling the landslide stress-strain state to predict landslide hazard and make management decisions under intensive and spatial development of the territories of Asian Russia are considered. Economic and spatial development of the territories concerning reorganization or formation of economically viable components of various production chains require careful consideration of their safe and continuous operation. In this respect, great attention is paid to the studies on exogenous geological processes under the complex geomorphic conditions that can have a substantial impact on the operation of production chain links.

The authors present a technique for modeling a landslide slope movement caused by anthropogenic impact. The revealed patterns in which influencing factors affect vertical displacements of landslide points created the conditions for their description at a new qualitative level. Mathematical modeling of landslide slope movement is based on the dynamic-type prediction model. This made it possible to predict the displacements of observed landslide points with sufficient accuracy. Based on a geo-cognitive safety monitoring of production chain links primarily important for the social and economic development of territories, the possibility of using the prediction models of the landslide slope stress-strain behavior as a "solver" in expert systems for forecasting landslide danger when making management decisions is shown.
\end{abstract}

\section{Keywords}

landslide slope, geodetic observation, mathematical modeling, prediction model, solver, spatial expert system.

\section{Declarations}




\section{Funding}

The study was funded by the Russian Federation represented by the Ministry of Science and Higher Education of Russia in the framework of project "Socio-Economic Development of Asian Russia on the Basis of Synergy of Transport Accessibility, System Knowledge of the Natural Resource Potential, Expanding Space of Inter-Regional Interactions”, Agreement no. 075-15-2020-804 dated 02.10.2020.

\section{Conflicts of interest/Competing interests}

Authors declare no conflict of interest

Availability of data and material

Not applicable

Code availability

Not applicable

\section{Acknowledgments}

The authors are grateful to Professor Yu. Gulyaev for the provided materials of long-term geodetic observations obtained by the Angara expedition as well as the editor and anonymous reviewers for their constructive criticism regarding the earlier version of the paper and valuable suggestions that have contributed to its improvement.

\section{Introduction}

Cutting-edge management models for regional and inter-regional economic and spatial development call for new scientifically valid methods and technologies.

The best practices in economic management prove that competitive strength can be achieved through the processes of horizontal and vertical regional integration where the development is triggered by the groups of companies and production chains rather than individual enterprises. Such an approach makes it possible to improve production and territorial management systems on various levels (Diao et al. 2009; Bell and Morse 2018; Han et al. 2021) but requires taking into consideration numerous factors that can slow down or even knock out the whole production chain for a long while. Considering that in Asian Russia the number of duplicate links of production chains is rather limited, control, monitoring, and safety of their operation become particularly important.

Presently, when numerous programs for the development of territories in Asian Russia are being elaborated, structured spatial data allowing automation and significant improvement of the quality of management decisions are of great demand. Such decisions, based on spatial expert systems (ES) and knowledge bases, make it possible to reveal the attractiveness of a certain territory, its economic capacity, possible weaknesses and environmental factors affecting the object under study, as well as establish their cause-effect relations (Diao et al. 2009; Atif et al. 2021). 
One of the dangerous factors that may highly negatively impact on a production chain link is geological phenomena - the most common natural and anthropogenic processes able to cease the operation of not only a single link but the whole production chain, causing major damage to regional or inter-regional industrial cluster. Hungr et al. (2014) believe that formation, identification and monitoring mechanisms, including timely identification of dangerous areas and mitigation of landslide consequences are the most important components for carrying out a qualitative assessment of the dynamics of natural and anthropogenic processes.

Schuster and Krizek (1978), and Van Den Eeckhaut et al. (2012) admit that the nature of landslide dynamics is exceptional and may be systematized and classified only within the limits of the monitoring zone having similar physical and geological characteristics.

The significance of complex research and mathematical modeling of slope processes is immense however, the engagement of geodetic observation methods is still underestimated. The latter would encompass not only observational data on downslope mass transfer, but some topographic information about land relief, slope orientation, other landscape properties, which have a significant impact on the downslope mass transfer. Simonyan (2011) summarizes and substantiates geodetic methods for studying landslide trends that allow carrying out high-degree control of different movements within general landslide areas, as well as their peculiarities. At the same time, geodetic data on movement compilation of monitored landslide points constitute an extraordinary valuable integral and quantitative characteristic is a result of a complex number of factor interaction, which defines the landslide behavior and dynamics. Such data are the basis for identifying certain patterns and features of a landslide process development. Moreover, the topography of land relief reflects the degree to which the gravitational forces influence landslide movement, while the orientation and other properties of the landslide define insolation level and seasonal pattern of the process dynamics.

Along with geodetic observations over landslide-prone slopes, there are other approaches and methods to register their movement and dynamics. At the same time, the type of a landslide process and the mechanism of landslide mass displacement define the choice of calculation equations, which is consequential to its geologic structure and soil elastic properties. Baborykin et al. (2015) describe some of the currently used methods for predicting landslide dynamics based on mathematical analysis under a number of assessment criteria of a digital terrain model (DTM) taken with certain weights. An interdisciplinary approach that uses geological, geomorphological and geotechnical data together with GIS capabilities (Federici et al. 2007; Ali et al. 2019) and includes data on a slope geometry and its direction, as well as landslide movement type and degree of its activity, along with the statistical analysis of a number of factors associated with the landslide and various efficient algorithms for its study, enables spatial modeling of certain layers of a landslide slope, identifying the degree of their instability, possible deadlines of their occurrence, movement, etc. Wen et al. (2017) used a least square support vector machine model (GA-LSSVM) together with an algorithm for streamlining model parameters to predict dynamics of 
landslide hazards in the vicinity of the Three Gorges Dam Reservoir; hence, trustworthy results of early prediction were obtained based on the case of Shuping landslide.

Analysis of literature shows that methods of monitoring and predicting means for landslide hazards are being developed in two areas: development of methods to predict the proneness of the territories under study to landslide hazard, and building efficient models for predicting dynamics of certain landslides. In a number of cases, the development of secondtype forecast models provides better results because they can predict future landslide behavior.

The issues related to mapping landslide-prone territories in the regions of Asian Russia are most relevant considering their geographical location, amounts of precipitation, significant temperature drops, rugged terrain, possible earthquakes, etc. That is why numerous research is devoted to efficient risk mitigation: implementation of machine learning methods and creation of algorithms for automatic detection of geologically hazardous areas. In this respect, the further types of machine learning models have proved themselves quite worthy. Spatial modeling of landslide hazards based on statistical analysis of the exposure factors used for solving multidimensional and nonlinear hazard prediction problems by building models based on decision trees is offered by Hosseinalizadeh et al. (2019). We consider support vector machine model (SVM) (Yousefi et al. 2015, 2020) together with the maximum entropy method (Boogar et al. 2019) as high-quality machine learning algorithms used for mapping landslide-prone areas with a quite high level of prediction accuracy. Greco et al. (2007), Yousefi et al. (2020), and Pourghasemi et al. (2020) analyzed the capabilities of a generalized linear model of multiple regression (GLM) and logistic regression model (LR). A model of boosted regression tree was developed by Yousefi et al. (2020), while Pourghasemi and Rossi (2017) used multivariate adaptive regression splines (MARS). To predict landslide hazards Yousefi et al. (2020) and Huang et al. (2018) also used the model of modified analytical hierarchy process (M-AHP), support vector machine model (SVM), frequency ratio model (FR) and the model of artificial neural network (Wang et al. 2016); a model based on the algorithm of fuzzy logic theory was offered by Akgun et al. (2012). It is important to note that there is a certain trend in applying an integrated approach to detecting landslide-prone areas that combines empirical and physical research methods (Do et al. 2020; Hsu et al. 2018). Bearing that in mind, we can see a connection between empirical landslide parameters (e.g. landslide body volume, terrain topography, geological and morphological distinctive feature) and physical models integrated in GIS (e.g. AHP, WoE, LR models) for further landslide susceptibility analysis (LSA).

Presently some papers provided profound research on identification of efficient methods for detecting landslideprone areas. Thus, after a comprehensive analysis of GLM, MARS GAM, and M-AHP machine learning models Pourghasemi and Rossi (2017), and Gayen et al. (2019) chose the M-AHP model as the most efficient. While studying the efficiency of SVM, MLP, RBF Neural Nets, KLR, and LMT models (Bui et al. 2016) for detecting landslide-prone areas, the MLP model was most efficient, while relatively small landslides were better detected with the KLR model and LMT 
logistic model tree. Huang et al. (2017) analyzed a number of models to predict landslide dynamics; they showed that an ELM multivariate model has some advantages over a linear and Chaotic PSO-SVM models, since predictions consider such triggers as amounts of rainfall and water level in the reservoir, which contribute to the displacement of a landslide body. Hong et al. (2015) compared two models used for mapping landslide hazards in Yihuang area, China: 2-class Kernel model of logistics regression (KLR) and a model of alternative decision tree; it is emphasized that when modeling landslide hazard, the ADT model ensures better high-quality results. Dou et al. (2020) discuss special aspects of SVM machine learning algorithms and their hybrid modifications for mapping the areas prone to landslide hazards; while comparing the four models, SVM-Boosting hybrid model proved to be the most efficient one. Application features of the two types of neuron network for mapping landslide-prone areas with the help of Levenberg-Marquardt learning algorithm and Bayesian regularization were discussed by Bui et al (2012). The calculated at the learning stage weights of the factors under analysis were later used to determine indices of landslide proneness; here the network model of Bayesian regularization turned out to be more efficient. Pradhan (2013), Kuzin and Sannikova (2016), and Huang et al. (2018) used the advantages of GIS for efficient landslide susceptibility analysis, the latter enables storing and processing topographic data, satellite images, field surveys, as well as features of geology, hydrology, climatology, vegetation, land cover, etc. Data analysis and processing with using various models based on GIS and machine learning algorithms allowed creating thematic layers of object-oriented data, calculating various indices and identifying weights of parameters for landslide susceptibility assessment.

Traditional approaches that use remote sensing technologies for building digital terrain models (DTM), based on joint use of photogrammetric, airborne (ALS) and terrestrial (TLS) laser scanning data, as well as instrumental data from GPS reference point network (Mantovani et al. 2013), provide researchers with tools for high-quality identification of various-type landslides and majority of the surface morphology features (Baborykin and Zhidilyaeva 2014; Shan and Toth 2018). At the same time, coprocessing of ALS data (before and after the event) together with long-period seismic recordings provides detailed landslide dynamics (Yamada et al. 2013). Godone et al. (2018) showed the capabilities of aerial laser scanning (LiDAR) for identifying unsteady slopes, their morphometric filtration, GIS processing and further mapping. Jaboyedoff et al. (2012) consider building precise high-resolution digital elevation models (HRDEM) or 3D models as highly attractive. Carter et al. (2001) showed that their combination with geological data allows predicting landslide areas that are susceptible to displacement, improving the quality of landslide mapping, revealing their morphological features (e.g., benches, slope profile, etc.). As for TLS technology, a number of specialized applications for interpretation of landslide formation mechanism, geotechnical properties of slope stability, their border detection and volume assessment were developed (Rowlands et al. 2003; Dunning et al. 2009; Mazzanti et al. 2018). Lately unmanned aerial vehicles (UAV) became ubiquitous, they allow getting real-time high-resolution aerial images that help identify and describe natural / anthropogenic hazards and terrain topography (Hu et al. 2019; Guo et al. 2020). UAVs equipped with a GPS-positioning system (RTK 
mode) ensure the capability for building a DTM, carrying out its automated analysis and following identification of terrain specific features in images (Ovsiuchenko and Akopov 2012; Godone et al. 2018). Westoby et al. (2012) and Cignetti et al. (2019) recommend using this technology for small-area landslides, which in combination with a MVS method allows building a high-resolution DTM capable to identify and map many geomorphological features generated by landslide evolution. For instance, Zeybek and Sanlioglu (2020) present their research related to building time-dependent DTMs based on post-processed UAV survey data with the use of radial basis function method to detect landslide displacements, which enables assessing the quality of the built DTMs by comparing them with the results of GPS measurements.

Numerous researchers apply various methods of mathematical modeling for predicting dynamic changes in ground water level to assess landslide stability. Chen et al. (2010) described the use of a SOM-RBFN multinodal model, combining self-organizing map theory (SOM) and radial basis function network (RBFN). Application of artificial neuron network (ANN) taught with the help of Bayesian regularization (BR) was studied by Mohanty et al. (2010). Gundogdu and Guney (2007) carried out spatial analysis of variation in ground water level with the help of multipurpose kriging and further empirical selection of models aligned with experimental models. To assess landslide slope stability Iverson (2000) offered to use a transitional model that has certain allowances related to variation in ground water pressure caused by rainfall; the model predicts fast and slow landslides if a number of factors are met. Bermúdez et al. (2009) offered a method of predicting time series with correlated errors at any specific time based on the Bayesian forecast approach, built upon multidimensional Halt-Winters model, that leads to the traditional model of multivariate regression. Duan et al. (2019) proved the connection between the parameters in the dynamic exponential smoothing model and outcomes of ground water variation due to changes in rainfall and water level in a reservoir allowing the description of deep-water landslide evolution. Jia et al. (2009) provide forecast results for ground water level based on the model that allows simulating a rise and a drop in the water level when studying physical behavior and destruction mode for saturated (unsaturated) sidelong ground. Periodic variation of water level and heavy rains are the key factors in landslide formation; here for modeling landslide formation Huang et al. (2016) used ES-MELM hybrid multivariate model that combined the capabilities of exponential smoothing (ES) and extreme machine learning (ELM) algorithms (Huang et al. 2017). Research results proved high efficiency of this model when forecasting landslide hazard. Sun et al. (2016) analyzed the variations of water level in dam reservoir and studied structural geological behavior of land abutment showing that changes in the latter influence variations in the groundwater level affect the stability of the reservoir slopes.

One of the key methods in studying landslide slope dynamics is numerical mathematical modeling. As source data, many researchers use a number of indices characterizing rock physical and mechanical properties. Thus, Liu et al. (2015) made a detailed analysis of several calculation options for studying slope stability, where they considered limit equilibrium method, elevated limit strength method, and strength reduction method (SRM).The methods differ in their input data and 
analytical models. As the result of the comparative analysis, the factors of safety, sliding surface shapes and positions were calculated. Based on the information about geometry and slope feature input parameters Kozhogulov et al. (2017) used the finite element method to calculate rock stress-strain behavior. Numerical simulation of the solid body destruction process, based on the hypoelastic behavior law and special technique for point bifurcation of a reference grid on a physical and mathematical model for the brittle hypoelastic medium (Nemirovich-Danchenko 2002) solved the problem concerning deformation and destruction of geologic environment, describing the processes of landslide formation. Guo et al. (2020) point out that a number of researchers regard numerical simulation for forces of complex landslide behavior from emergence to its complete stop in the context of topography change. Moretti et al. (2015) modeled topography change and soil erosion along the slope as well as changing soil composition of a moving landslide and later compared them with signals from the seismic network in order to obtain detailed information about changes in landslide velocity, mass and volume. Bai et al. (2019) used numerical simulation method combining DTM and seismic data to calculate friction coefficients for every stage of landslide movement as well as its volume and the area of focus, erosion, landslide, and accumulation zones.

Methods and approaches developed over the recent decades are based on processing of seismic signals for obtaining unique information about the time of landslide occurrence, its features, and behavior evolution. Most current studies (Allstadt 2013; Lin 2015; Fuchs et al. 2018) are based on the relevant processing of long-period seismic waves received from a network of active seismic stations. At the same time, Allstadt (2013) and Moretti et al. (2015) used signal conversion results together with field survey data to predict the time of landslide occurrence. In a number of cases they managed to associate high-frequency signals with topography changes due to increased stirring of landslide forming materials during its movement. Lin (2015) and Fuchs et al. (2018) applied direct modeling of signals for assessing landslide mass and acceleration, as well as interpretation of sequence of events. The second approach is based on studying high-frequency signals that are more typical for a wide range of different size landslides, provided they are in the close proximity to the scene. Due to a rather complicated mechanism of a signal source, topography, and sideline diverse landslide energy scattering effects, such as friction, cracking, and plastic deformation, this approach is less applicable for further interpretation (Manconi et al. 2016). At the same time, Walter et al. (2012) used this type of signals when evaluating landslide mass and acceleration, detection of sliding surface material over various travel sections. For landslide seismic signal recognition Yan et al. (2020) and Fuchs et al. (2018) suggest analyzing signal frequency-time characteristics resulting from Fourier transform (STFT) together with band-pass filter and phase coincidence detector STA/LTA. Feng et al. (2017) implement the method of numerical simulation for processing seismic signals with the help of Hilbert-Huang transform that, coupled with field survey data, enables restoring landslide process dynamics and defining its spatiotemporal characteristics. Guinau et al. (2019) used joint processing of seismic signals and remote sensing data for calculating landslide volume, detecting its structural changes, and monitoring of unstable slopes. 
The use of machine learning decision algorithms pre-trained on well-known datasets and data received from regional seismic networks is quite efficient and will allow identifying seismic waves taken from already existing database that covers all possible types of events (Hilbert et al. 2014) and implementing automatic detection of an event type with high accuracy. For instance, Dammeier et al. (2011) presented results of their work where they analyzed signals received from the network of continuously operating seismic stations. Within their research, they used multivariate linear regression methods to calculate characteristics of seismic signals and key parameters of a landslide (drop height, volume, beating, potential energy), which further were verified on known datasets. The obtained results showed that this technique may be used for automatic classification when detecting such events in the future.

Over the past decades, a 3D analysis has been used when calculating a slope stability. Meanwhile a number of 3D slope stability evaluation methods based on numerical simulation and other approaches were offered. Dong, Hu and Song (2018) presented some predicted results for landslide slope stability based on 3D geological and geotechnical technologies and models of numerical simulation, while Sari et al. (2020) evaluated slope stability analysis by using the concept of the ultimate rock equilibrium and calculating the displacement resistance coefficient. Zhang et al. (2016) examined some approaches to detecting landslide process activation and identified key factors that cause landslide mass displacement, which later were used for building physical and mathematical models and carrying out necessary calculations. They also showed strengths and weaknesses of different calculation methods (finite element limit equilibrium method, slices method and finite element strength reduction method) when evaluating the three cases of stability analysis, i.e. natural slope, anchored slope with seepage, and excavation anchored slope. After the calculation of sliding surface depth, safety factor and anchoring effect parameters, the SRM method proved to be most efficient.

Nowadays, in order to detect the beginning of landslide occurrence and movement, special emphasis is given to the development of real-time landslide monitoring systems. An example would be an AI-based monitoring system containing different monitoring elements to obtain the data needed for analysis and DeepAR mathematical probabilistic-type prediction model (Dong et al., 2021) based on comprehensive time series analysis. In this context, Dammeier et al. (2016) point out that automatic detection and classification of big and small landslides in Central Switzerland based on hidden Markov models (HMM) when processing registered seismic data is of great interest. HMM together with event evaluation and event localization methods (i.e. a hybrid model) can be an efficient tool for real-time detection of landslide hazard or risk.

Special interest is paid to insufficiently studied landslide slope dynamics prone to anthropogenic influence. As a rule, there are only nonsystematic geodetic observations of a landslide movement and a lack of quantitative and descriptive characteristics of spatiotemporal parameters presenting anthropogenic influence. It is obvious that the lack of source data makes the identification of patterns for landslide development particularly difficult. The opportunity to use mathematical models to describe landslide movement taking into consideration such influencing anthropogenic factors as blasting and 
changes caused by excavated soil creates unique conditions for mathematical modeling when predicting landslide processes. Thus, we believe that any stage of landslide development should be simulated with mathematical models and data of geodetic and monitoring observations over the changes in anthropogenic impacts.

The main idea of the proposed approach is that mathematical modeling of landslide dynamics influenced by natural and anthropogenic factors in the context of limited and insufficient source data could become an efficient "solver" used in spatial expert systems to oversee the state and manage safety of industrial facilities. The research is pursuing the following objectives: (i) develop a technique to single out positive and negative landslide movement components caused by anthropogenic factors; (ii) justify the choice of key influencing factors causing landslide movement, i.e. blasting operations and removal of great amount of soil; (iii) build a dynamic mathematical prediction model represented by two first conditional moment functions of the movement process to predict displacements of the observed landslide points; (iiii) apply the developed technique using it as a "solver" in a spatial ES generating management decisions in order to prevent emergencies at the key links of various production chains which may have a negative impact on the economic sustainability of regional and inter-regional interaction.

\section{Materials and methods}

\subsection{Investigated processes: general information}

The analyzed landslides developed on the right-side slope of the Angara River, in the construction section of the rockfill dam of the Boguchanskaya hydroelectric power plant (HPP) - a key link of several production chains that have strategic significance. The left riverbank is composed of basaltic rocks, the displacements of fixed geodetic points occurred there only during quarry blasting operations.

To a certain extent, landslides are related to the geology of the right bank where sedimentary rocks of binominal structure slop down to the river at angles varying from 5 to $15^{\circ}$. The upper part of the slope is composed of Ordovician hard rocks while the underlying Cambrian sediments are soft clayed argillite and marlstones prone to plastic deformations caused by changing groundwaters. Thus, the underlying clayed rocks form a sliding surface. Overall, the analyzed landslide zone can be considered homogenous in terms of its geological structure. Natural heterogeneity of landslide displacements in the analyzed area is caused by differences in slope steepness, seasonal climatic changes and tectonic disturbance. According to the classification offered by Hungr et al. (2014) landslides on the right bank slope of the Angara River in the dam section of the Boguchanskaya HPP can be classified as plastic.

The study object was the only landslide slope where geodetic observations (III class leveling) of vertical displacements of two groups of intact landslide points $(8021,8022,8023,8024,8025)$ and $(8061,8062,8063)($ Fig. 1) were carried out for nine years. The observations covered a 2.5 (along) by 1.5 (across) km strip of the riverbank. Initially, there were 
reasons to assume that major factors affecting the movement of large soil masses to the earth deposits of the dam and groundwater-level changes were caused by blasting works carried out within the period of geodetic observations.

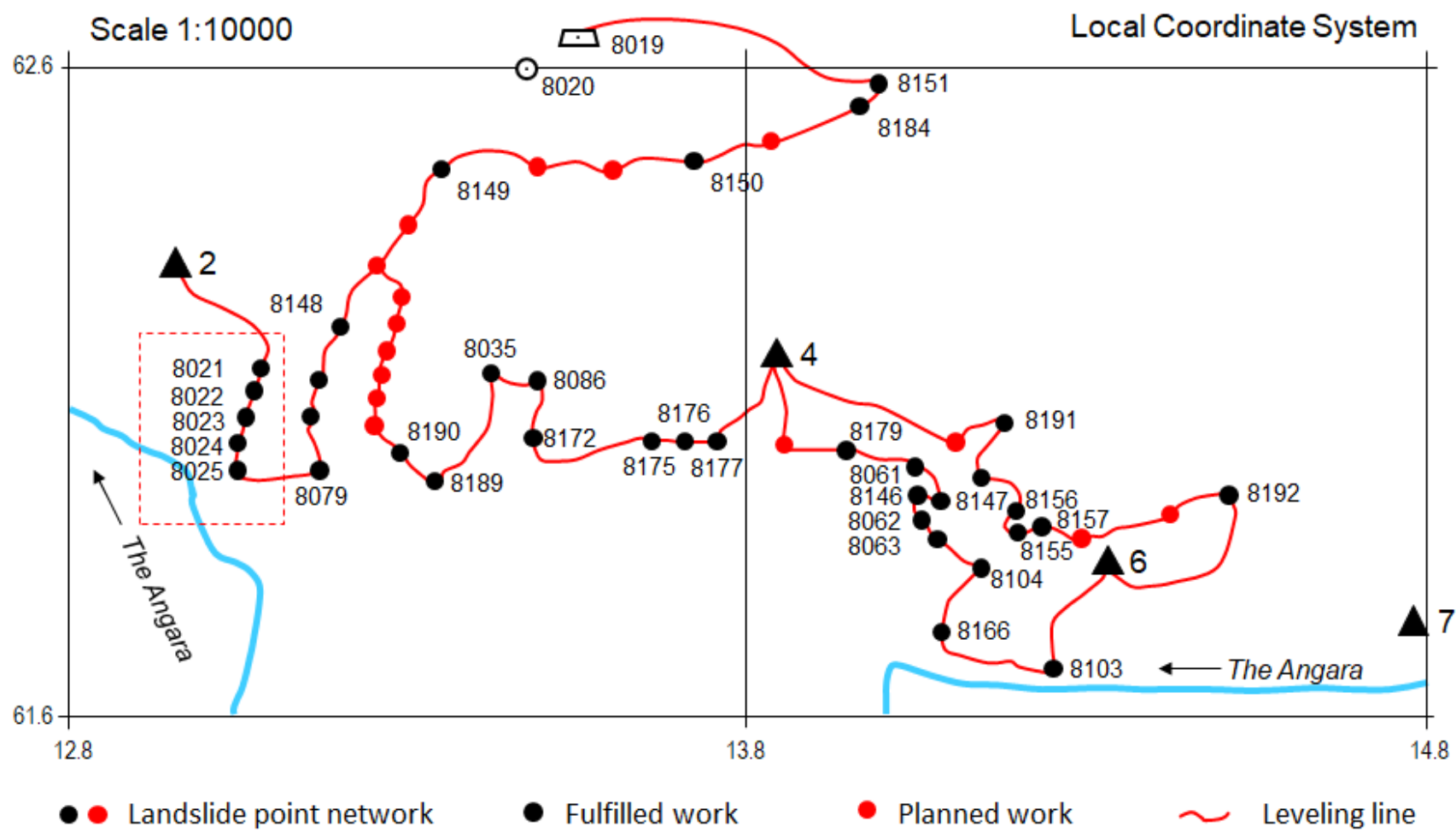

Figure 1. Schematic view of the landslide reference point network

At the same time, there was no specific information about the place, time and power of the blasts as well as unloading of landslide. Further analysis confirmed the assumptions about the anthropogenic impact upon vertical and horizontal displacements of landslide points. Moreover, blasting triggered water-level fluctuations in the Angara and groundwater levels.

Particular attention should be paid to assessing the impact of a landslide slope unloading due to removal of soil from rock quarries since it has an ambiguous effect on landslide development. On the one hand, removal of soil decreases the weight of bank masses and reduces the slope tangent (active force component), which enhances the slope sustainability. On the other hand, it affects gravitational force and decreases friction making the landslide move faster.

Water-level fluctuations in the Angara and groundwater levels, changes of solar radiation and ambient temperature, precipitation, number and power of blasts, volume of removed soil can also be considered as important factors, which are often interconnected and affect landslide point displacements indirectly. Further studies in this field will give better understanding of a land-sliding mechanism and help substantiate reliable forecasts based on the analysis and assessment of the latter.

\subsection{Hydrological instability assessment of the right bank of the Angara in the dam landfall area}

The general picture and possibility to assess landslides based on accumulated observations can be represented as: 
- rocks fall towards the Angara at an angle up to $15^{\circ}$, series of tectonic disturbance in the work area create preconditions for the occurrence of landslides;

- having low inner friction and soil adhesion coefficients weak rocks are prone to plastic deformations, which determines scale, place and time of landslide occurrence depending on natural and anthropogenic impacts;

- due to significant heterogeneity of the lithological composition of the rocks, their jointing, degree and time of water intrusion, as well as the influence of adverse stochastic factors, deterministic forecast of the location, scale and duration of a landslide event applying the known methods of rock and soil mechanics is impossible.

To provide reliable assessment and prediction of landslide behavior based on quantitative data of geodetic and other observations it is necessary to carry out a qualitative assessment of the impact of a number of natural and anthropogenic factors upon general regularities of landslide development. In this context, we will assess the impact of hydrological conditions, atmospheric precipitation and blasting on the landslide processes. Subterranean waters combined with the outlined above conditions determine a wide range of landslide events to a larger extent:

- a perched water table may occur above the Angara water line and the level of underground waters, i.e., nearly everywhere in the aeration zone when there are interlayers and relatively thin layers of low-permeability rocks. Such type of subterranean waters caused the largest local landslides;

- vast sliding surfaces may develop in the zone of groundwater level fluctuations induced by precipitations and fluctuations of the Angara level. Monoclinal rock formation above the Angara water line allows us to consider such surface as "flat", and the power of landslide blocks overspreads from the earth surface to the average subterranean water level;

- the position of soft clayed semi-rocks below the subterranean water level, weakening effect of hydrostatic weighing due to confined groundwaters and regional tectonic disturbance create conditions for the occurrence of big regional landslides with sliding step-like or curvilinear surface below the Angara water line. These landslide movements, combined with smaller surface shifting, are the greatest threat for the right-bank dam abutment of the Boguchanskaya HPP, which is practically the only energy hub for all regional production chains. In this regard, we will point out that for nine years of geodetic observations we registered slight displacements of the existing geodetic reference network points, which confirms the existence of regional blocs.

Atmospheric precipitation and moisture of the weakened layers have little impact upon landslide behavior in the aeration area, but they form a perched water table, which influences the development of local landslides.

Blasting operations on the right bank of the Angara influence landslide development through subterranean waters. Direct impact is exercised through primary and cross waves in rocks, the degree of their impact depends on the explosion capacity and the distance from the weakened areas. Blasting impact occurs through fluctuations of ground or pressure waters of the piezometric level when primary waves influence upon water-bearing rocks. At the same time, the impact of an- 
thropogenic groundwater fluctuations upon landslide behavior is insignificant if compared with natural ones, since their impact time and amplitude are relatively small.

Changing the piezometric level, which characterizes the varying hydrostatic weighing of rocks (interchange influence of overlying rocks upon a weakened layer), aggravates the impact of confined groundwaters towards the development of regional landslides. To a certain extent, this circumstance can be regarded as the occurrence of induced seismicity.

The above geotechnical assessment of the impact of prevailing conditions and main influencing factors upon landslide development reveals some obstacles preventing univocal interpretation of the observed landslide processes using geodetic methods of observation.

\subsection{Dynamic mathematical model}

Dynamic mathematical models describe deformations taking into consideration joint effect of time and main influencing factors. Predicted results of mathematical models can become one of the key tools used as a "solver" in spatial expert systems when shaping knowledge about the state of a link of a particular regional or interregional production chain. In this regard, dynamic models are more advantageous since they have flexible structure that matches the physical essence of the developed process and takes into account inertial interaction both landslide process and influencing factors and their temporal changes (Khoroshilov 2018). For instance, a second-order lag input-output model that describes the movement of a randomly selected landslide point caused by two main influencing factors is defined by the following recurrent expression:

$$
x_{k}=\varphi_{1} x_{k-1}+\varphi_{2} x_{k-2}+\beta_{1} Z_{\kappa}+\beta_{2} V_{k}+\gamma \omega_{k}
$$

where $x_{k}$ is an output variable, i.e., the value of a landslide point shift at the $k^{\text {th }}$ quantization interval;

$Z_{k}, V_{k}$ - input expressed as values of two main influencing factors (changes in the blasting charge mass and the volume of extracted soil);

$\omega_{k}$ - noise component;

$\varphi_{1}, \varphi_{2}$ - dynamic factors showing the impact degree upon movement $x_{k}$ of the values $x_{k-1}, x_{k-2}$ accordingly;

$\beta_{1}, \beta_{2}, \gamma$ - factors characterizing the extent of impact of $Z_{k}, V_{k}$ and $\omega_{k}$ values upon $x_{k}$.

The model parameters are assessed with stage-by-stage MLS by approximating the two first moment functions. At the initial stage the model parameters are assessed as a result of minimizing the functionality: $F\left(\varphi_{1}, \varphi_{2}, \beta_{1}, \beta_{2}\right)=\sum_{k=2}^{N}\left(x_{k}-\hat{x}_{k / k-1}\right)^{2}$, for which conditional mathematical expectation is presented as $M\left\{x_{k} / x_{k-1}, u_{k}\right\}=\hat{x}_{k / k-1}=\hat{\varphi}_{1} x_{k-1}+\hat{\varphi}_{2} x_{k-2}+\hat{\beta}_{1} Z_{k}+\hat{\beta}_{2} V_{k}$. At the same time, parameters $\hat{\varphi}_{1}, \hat{\varphi}_{2}, \hat{\beta}_{1}, \hat{\beta}_{2}$ 
are estimated by solving the relevant system of normal equations. At the final stage, the functionality expressed through the conditional correlation function is minimized.

To define the order of an auto-regression model and execute the final estimation stage, asymptotically unbiased estimates of the correlation function are calculated on residual modeling errors with using the expression (Box et al. 2015):

$$
K_{\varepsilon}[m]=\frac{1}{N} \sum_{k=1}^{N-m} \varepsilon_{k} \varepsilon_{k+m}
$$

where time shift $m=0,1,2 \ldots M<N$.

Residual errors $\varepsilon_{k}$ can be found as difference between actual displacements and their relevant approximated values calculated on the models:

$$
\varepsilon_{k}=x_{k}-\hat{x}_{k / k-1}=\gamma \omega_{k-1}
$$

The choice of an auto-regression order is based on the correlation function graphs. In our case, the following model can be used (Box et al., 2015):

$$
\omega_{k}=\mu \omega_{k-1}+\eta \omega_{k-2}+\xi_{k}
$$

where: $\mu, \eta$ are estimated parameters.

Khoroshilov (2018) recommends estimating parameters $\mu, \eta$ by minimizing the functionality:

$$
F_{2}(\mu, \eta)=\sum_{m=1}^{M}\left(\hat{K}_{\varepsilon}[m]-\mu \hat{K}_{\varepsilon}[m-1]-\eta \hat{K}_{\varepsilon}[m-2]\right)^{2}
$$

\subsection{Analysis of landslide geodetic observation}

In most cases, data were processed by applying methods of mathematical statistics (correlation analysis). Statistically homogenous groups of displacements were removed from the data array. To assess the homogeneity of landslide displacement groups the variation coefficient $W_{x}$, characterizing the relative dispersion degree of the values of the analyzed indication $x_{i}, i=1,2, \ldots, n$ (Pavlovskaya et al. 2012), was used. It is obvious that a greater degree of dispersion indicates higher heterogeneity of characteristic values. A set of indications was taken as homogenous if $W_{x} \leq 0.33$. The displacement speed of landslide points $V_{x}$ was chosen for analysis since their temporal changes, monitored with geodetic observations, were often measured at different inter-cycle intervals $\tau_{j}$. Transition from displacement values to their speed enables to normalize the analyzed landslide development process and estimate changes of its major parameter. Such statistical approach to revealing the intensification of landslide development allows predicting the position of landslide points for any chosen moment of time. It should be noted that in statistical processing the observed landslide slope movements were considered as deterministic and statistically distributed when sample representativeness was determined by statistical homogeneity rather than the sample size. 
Analysis of geodynamic processes monitored with multiple cycle observations over the displacement of local geodetic network points must be accompanied by assuring the stability of particular network points. However, it is extremely difficult and often impossible to provide absolute point stability within local geodetic networks; at the same time, mutual point stability can be provided. In this case, definition of displacement values and their directions lose their initial meaning making the vector representation of displacements useless for analysis and interpretation, since transition from one conditional network to another entails the reorientation of vectors.

At the same time, observation inter-cycle time intervals differed significantly and did not follow the extremums of anthropogenic impacts. Even in conditions of such incomplete information, negative and positive vertical displacements of reference points were found out (Khoroshilov et al. 2013). It is obvious that natural downward sliding, considerably increased by blasting, caused negative displacements. In its turn, soil softening after the removing and following discharge of so-called overburden pressure caused positive displacements.

At the initial stage, the positive and negative trends of temporal developments upon the impact of anthropogenic factors were approximated with $4^{\text {th }}$ and $5^{\text {th }}$ degree polynoms having sufficiently tight dependence. Such approximation was only a mathematical description of the observed process that did not synthesize overall trends of its development sufficiently. Therefore, the trends can be used only for a rough forecast of a landslide slope dynamics, since it is impossible to identify place, time and impact level with using the graph of the observed response.

To confirm the discovered specifics of the response of the landslide slope to blasting and unloading, we adjusted the heights of all reference points of the analyzed landslide network using the method offered by Fedoseev (Klyushin et al., 1993). Under the conditions of mutual instability of shifting points, this enabled to define relative displacements of reference points and their actual heights. By using adjusted heights, we calculated the speeds of reference point inter-cycle displacements and estimated their accuracy. In such a way, all monitored parameters of the landslide process were normalized, which enabled to carry out the comparative analysis of its development regardless the duration of the inter-cycle intervals.

The regularities of cinematic development of the isolated centered process were defined by using the correlation theory of random functions (random parameter distribution law). First, we estimated and ensured the process normality for each section. Zero mathematical expectation of the centered process trend determined its linearity at all modeled sections. As a result, the temporal development of standard and normalized auto-correlation function was approximated. Later, the identified trends allowed assessing the expected landslide dynamics in similar conditions.

\section{Results}

\subsection{Spectral assessment of the effect of influencing factors}

To estimate the impact of anthropogenic and some meteorological factors (having harmonic temporal development) upon displacement of landslide reference points, mathematical tools for spectral analysis of time series were used. The es- 
sence of spectral analysis was to represent a set of operations enabling to present periodic function $X(t)$ as a sum of harmonic components and define their parameters. According to Jenkins and Watts (1969) the time sequence was represented as series:

$$
X(t)=A_{0}+2 \sum_{k=1}^{N}\left(a_{k} \cos 2 \pi f_{k} t+b_{k} \sin 2 \pi f_{k} t\right),
$$

where $f_{k}=K / T$ - frequency; $T$ - harmonic process period; $K=1,2,3 \ldots N ; a_{k}, b_{k}$ - actual and false spectrum components that can be calculated as:

$$
\begin{aligned}
& a_{k}=\frac{2}{N} \sum_{n=0}^{N}\left(t_{n}\right) \cos \frac{2 \pi K t_{n}}{N}, \\
& b_{k}=\frac{2}{N} \sum_{n=0}^{N}\left(t_{n}\right) \sin \frac{2 \pi K t_{n}}{N},
\end{aligned}
$$

here $N$ is the number of samples.

The amplitude characteristic was considered as

$$
A_{k}=\sqrt{a_{k}^{2}+b_{k}^{2}}
$$

Amplitude-frequency dependence can be represented graphically, where harmonic frequencies are plotted along one axis, and their amplitude characteristics are plotted along the other axis. Analysis of a harmonic spectrogram, by breaking it into several characteristic zones, makes it possible to find out the frequency of each harmonic, its period and amplitude. By restoring the analyzed function with inverse Fourier transform in the low-frequency vibration spectra, it is possible to identify the main trend of the analyzed process (i.e., function inclination to time axis), and from calculated characteristics to carry out the analysis of landslide slope deformation process described with a dynamic model. At this stage, the problems related to finding out the impact level of the influencing factors upon the value of displacements of landslide points are solved.

The following analysis procedure was used in the study:

- calculation of Fourier transform of the analyzed function;

- graphical representation of the amplitude spectrum (spectrogram);

- breaking down the spectrogram into characteristic zones;

- calculation of the period of each harmonics (based on its frequency);

- performing inverse Fourier transform in the low-frequency vibration zone to get the trends of the studied process;

- identification of correlating processes by comparing their spectrograms. 
We used this mathematical apparatus to analyze time series of the vertical displacements of two statistically homogenous groups of landslide points $(8021,8022,8023,8024,8025$ - group one; 8061, 8062, 8063 - group two) as well as relevant influencing factors (water level in the Angara, monthly mean temperature, average daily atmospheric precipitation, amount of removed soil, amount of blasting charge). We also considered the spectra of other meteorological factors (changes in the level of groundwaters, changes in atmospheric pressure) and spectra of horizontal displacements of landslide reference points. The obtained spectrograms are shown in Fig. 2-4.

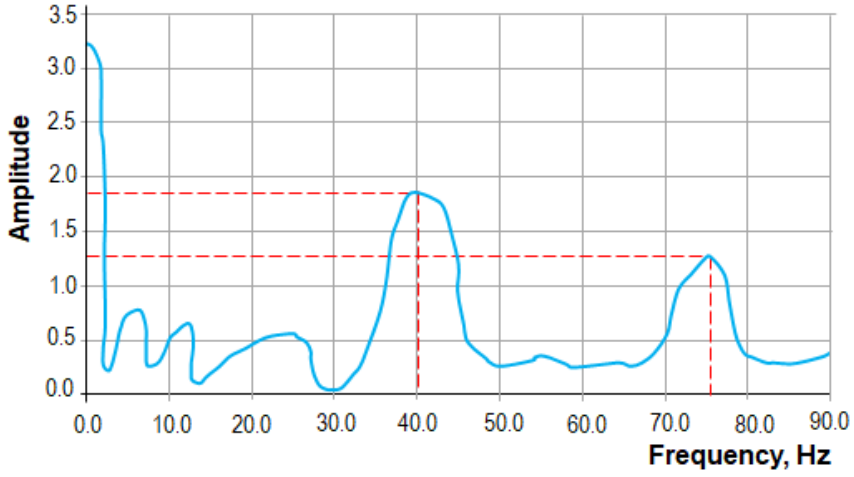

a

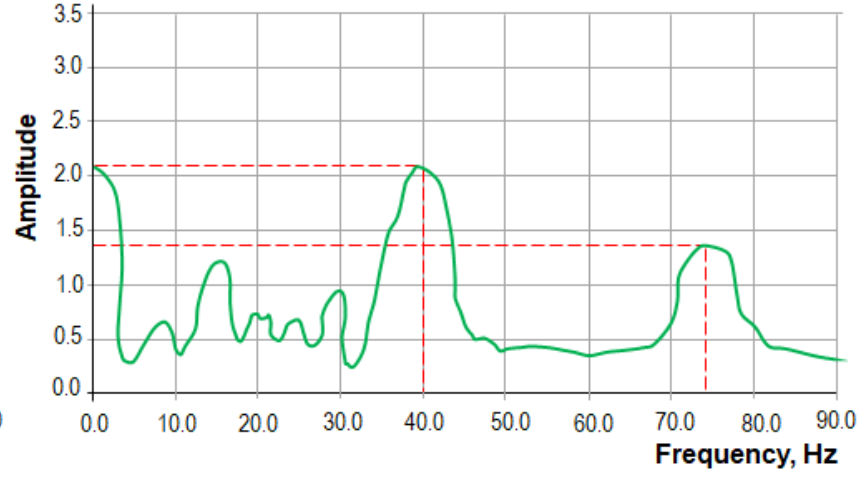

b

Figure 2. Vertical displacement spectrograms of (a) group 1 landslide points; (b) group 2 landslide points

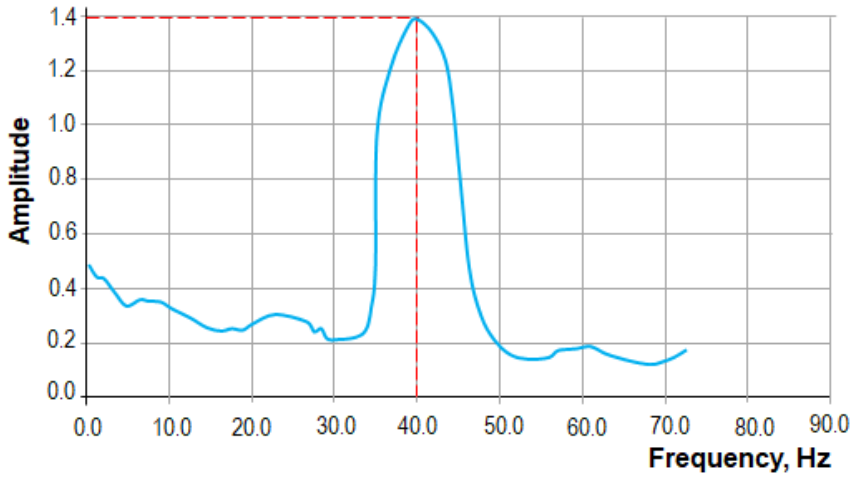

a

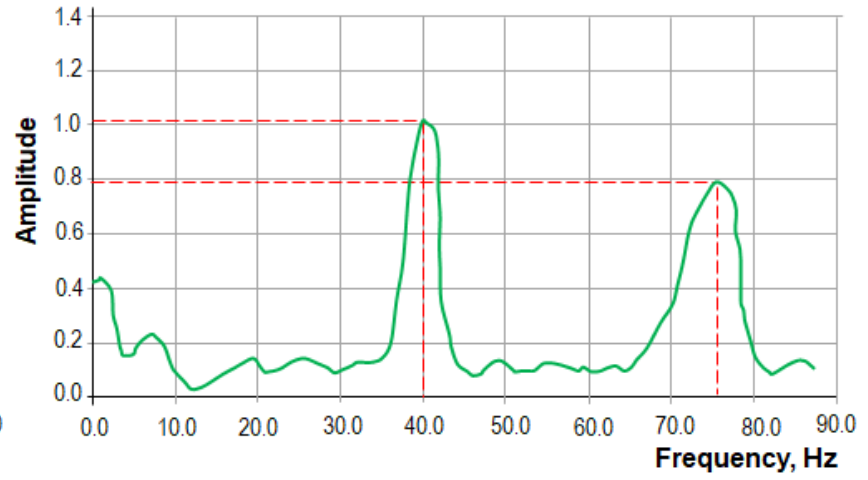

b

Figure 3. Vertical displacements triggered by the (a) volume of removed soil; (b) amount of blasting charge

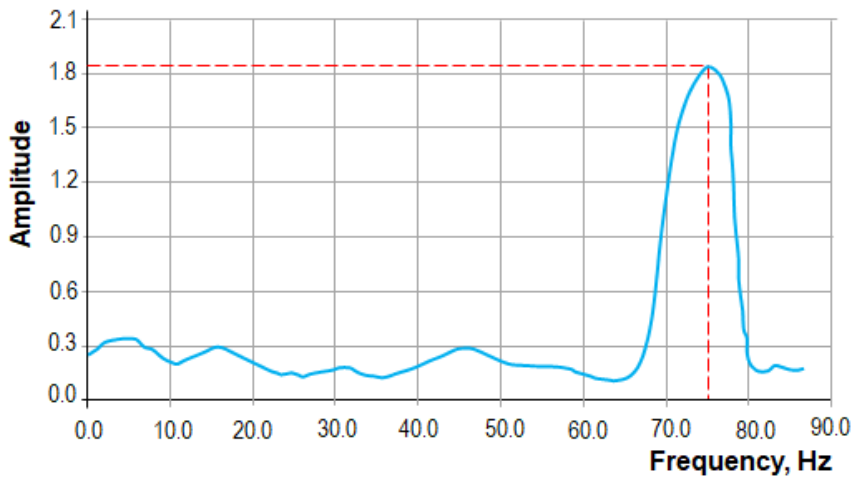

a

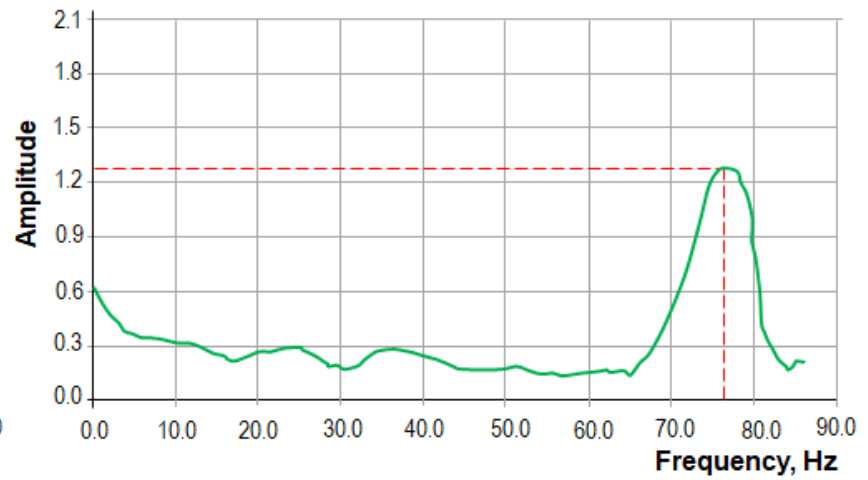

b

Figure 4. Vertical displacements caused by changes of (a) air temperature; (b) the Angara water level

\subsection{Landslide slope movement: separate modeling}


The technique for the assessment of landslide slope dynamics consists of two parts (Khoroshilov et al. 2013). The first was aimed at finding invariants of the most stable reference points within the group of landslide points; the second, based on the results of geodetic observations, was focused on landslide susceptibility assessment. Finding the invariants of the most stable landslide points increased the credibility of an actual picture of a landslide development because of the lack of geodetic information.

To study mutual stability of the reference points we applied the method developed by Yu. Fedoseev (Klyushin et al., 1993) where using inter-cycle fluctuations of heights of the observed group of landslide points in the system of their average height enables to not only identify unstable reference points but also determine the size of their displacement. The method helped adjust the heights of all observed landslide points and obtain their actual heights by separate modeling of negative and positive trends of displacements reflecting different nature of landslide reaction to blasting and unloading of slope (Fig. 5, 6)

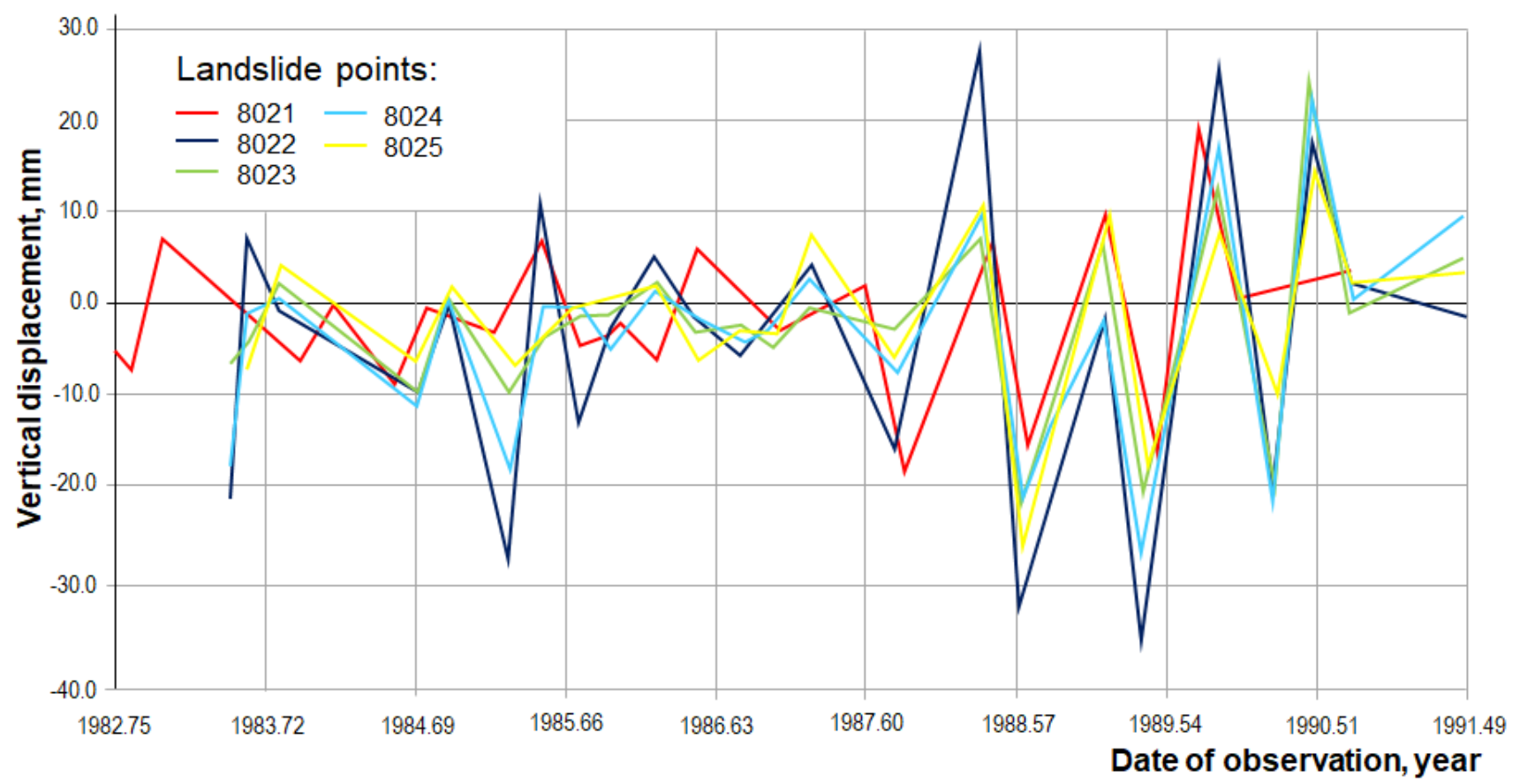

Figure 5. Vertical landslide point displacements caused by blasting and unloading of slope

The next stage was the transition from the values of displacements observed at different times in inter-cycle intervals to the displacement speed, relying on the adjusted heights of the landslide points. Thus, the monitored parameters of the landslide process were normalized regardless the inter-cycle time intervals. A comparative analysis of the obtained results showed that displacement speed values of only 24 of 120 cases were less than their calculation error. The proximity of the displacement speed values and their errors were caused by low speeds at short inter-cycle time intervals and insufficient accuracy of the third class leveling used for geodetic observations. At the same time, the fact that the values of positive displacement speed decreased due to the natural downward landslide movement during unloading of the slope, while negative speed decreased under the inertial impact of the preceding unloading of the slope was also taken into account. This proved 
the opposite-sign response of the landslide slope to blasting and unloading impacts, which formed the grounds for separate consideration of negative and positive elements of vertical displacements at the next stage of the study in accordance with the determination and probabilistic nature of the landslide process. Fig. 6 shows the development of negative and positive trends of temporal landslide displacements.

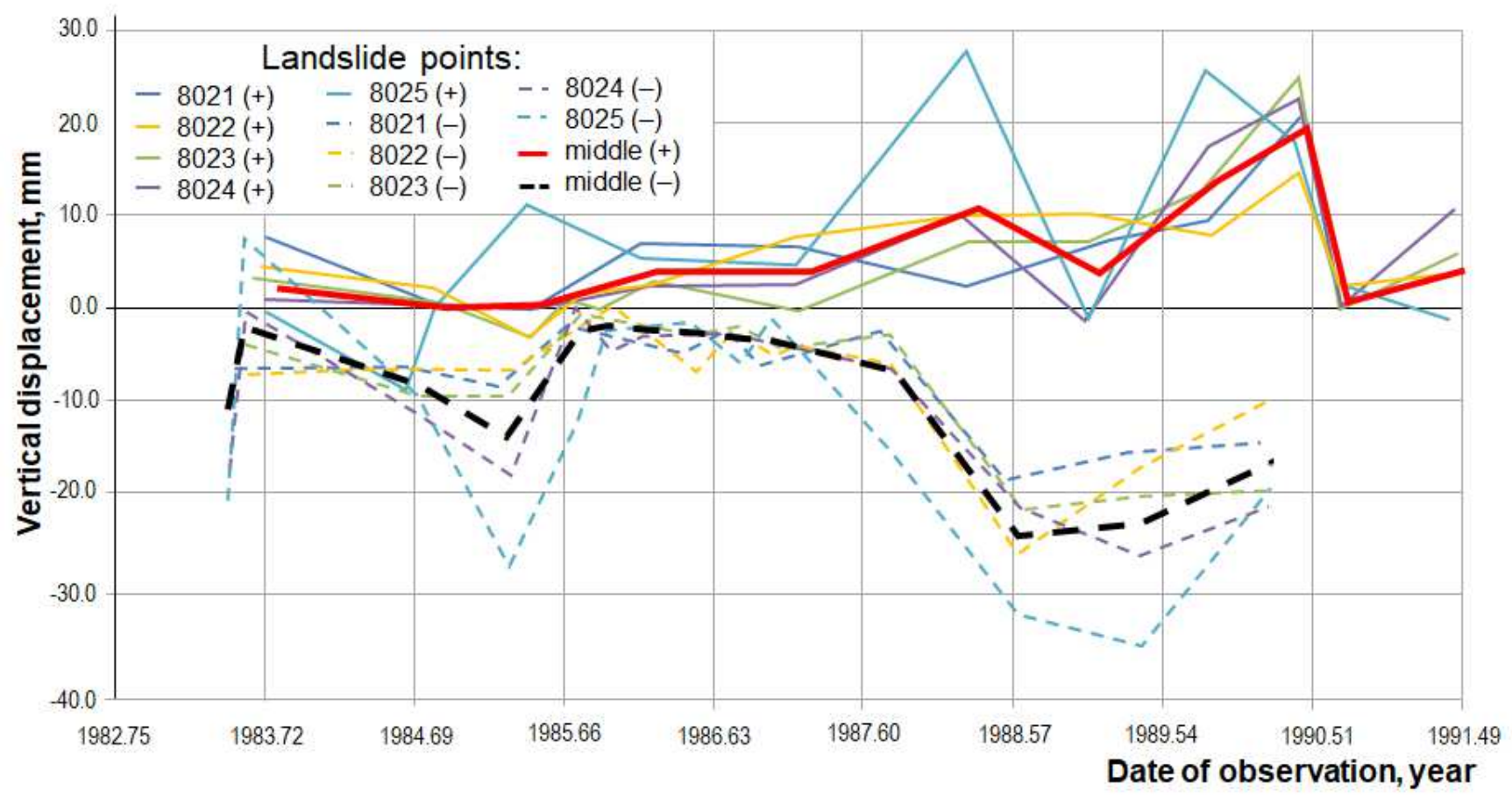

Figure 6. Results of separate modeling of negative and positive components of the vertical displacement process

Then, separate centering of the process components was carried out; this allowed revealing the nature of two types of anthropogenic impacts as temporal changes of the average displacement values fixed by observations (Fig. 7, 8).

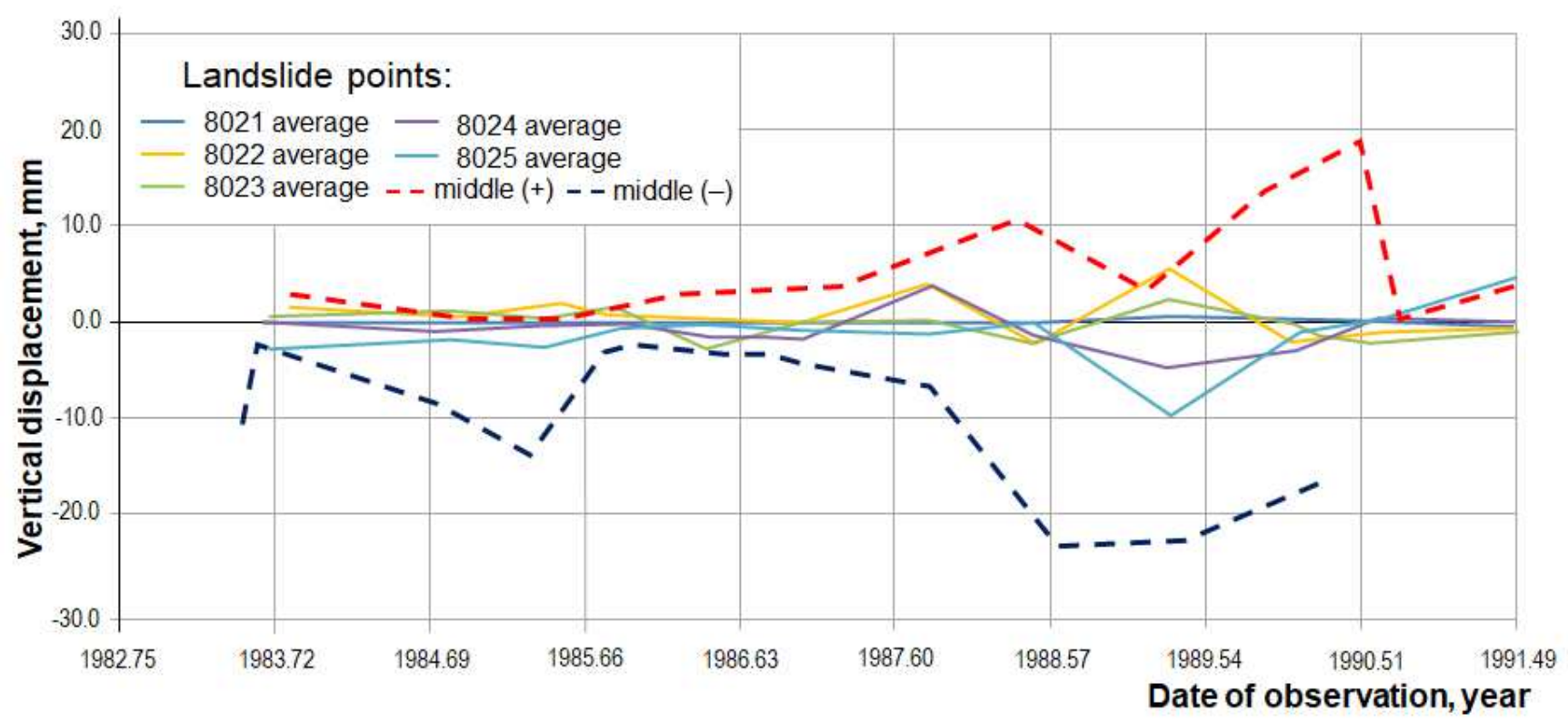

Figure 7. Centering of the average component of the vertical displacement process caused by blasting and unloading of slopes 
Centered values of the negative component of the process had mainly the positive development trend, and the positive component of the process - the negative one, which confirmed the mentioned above compensatory and inertial effects of the influencing factors. Interpretation of landslide slope positive response to its unloading relies on the experience of geodetic monitoring over the rise of a deep construction pit bottom of high-rise buildings. The rise occurs due to soil softening after the removal of natural soil pressure.

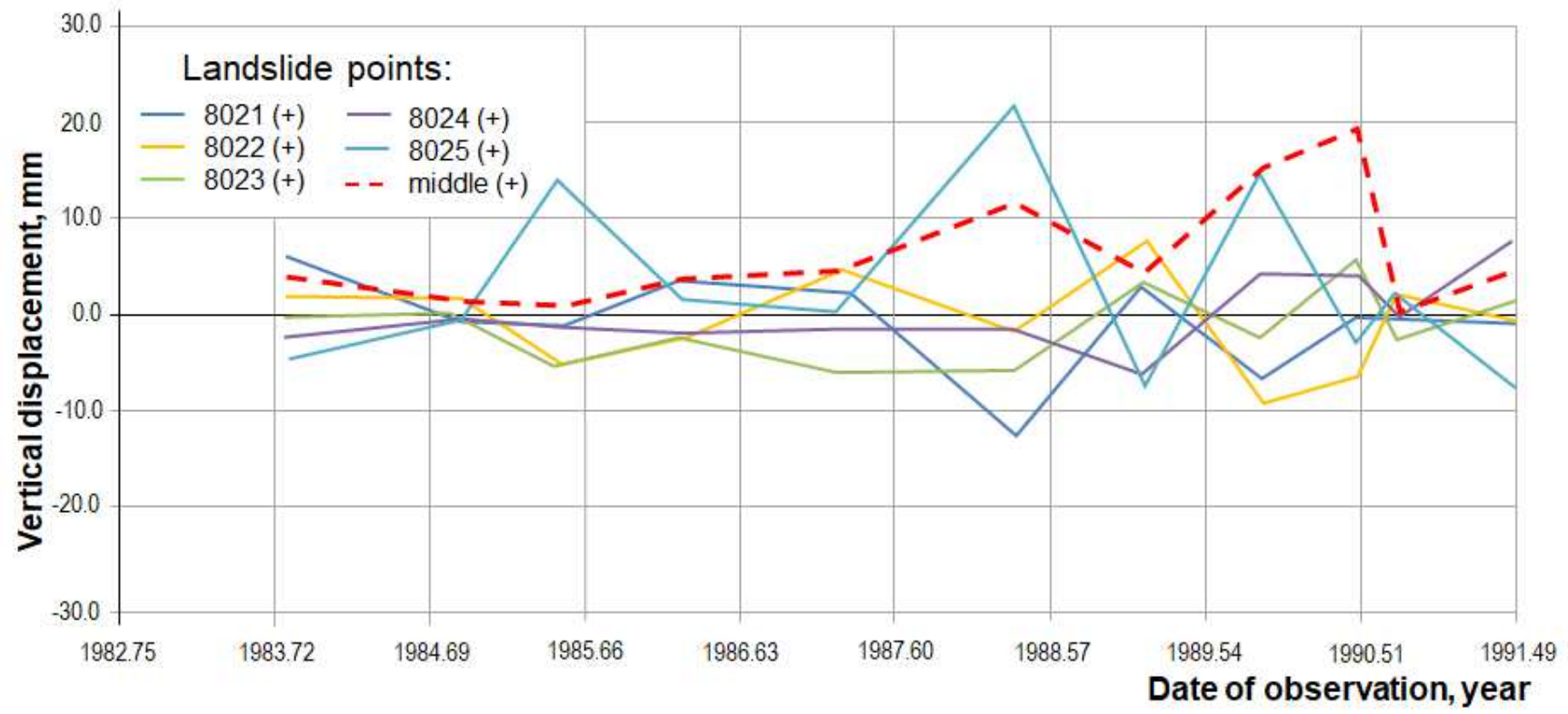

Figure 8. Centering of the negative component of the process of vertical displacements during blasting and unloading of slopes

It is obvious that blasting impacts only enhance natural motion of landslide soil masses. At the same time, the centered values of both components of the process development demonstrate mainly natural character with a small share of anthropogenic impacts. Therefore, they turned out to be close to each other, which enabled to integrate the centered process into five implementations by averaging its values over closely adjacent sections and including values of several distant sections.

We should note the following important circumstance. Separate centering of negative and positive landslide slope displacements enabled to identify earlier unknown characteristics of temporal and intensity impact of two main influencing factors (anthropogenic impacts) that caused changes in the average displacement values of the observed landslide points (geodetic observations). The calculated centered values of negative and positive displacement components characterize the development of the landslide process with no anthropogenic impact and can be considered as components of an overall process (Fig. 9).

Carried out studies and calculations enabled to accomplish the parametric dynamic identification of an analyzed landslide process by splitting it into positive and negative components reflecting the response to the main anthropogenic influencing factors. 


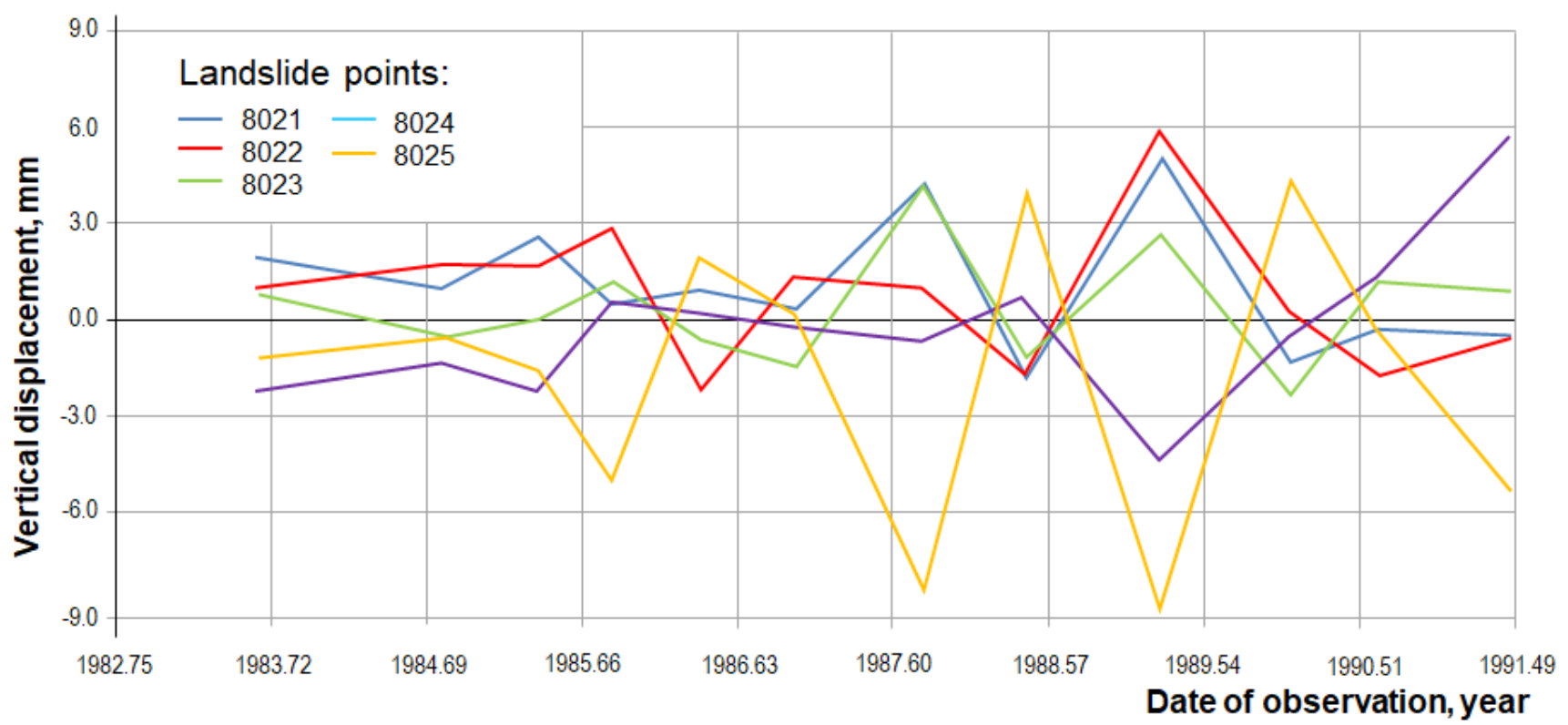

Figure 9. Combined centered process of positive and negative components presented in five implementations

The follow-up procedure was the modeling of five centered dynamic implementations of the landslide process represented as time approximated mathematical expectation.

\subsection{Modeling anthropogenic displacements (prediction mathematical modeling)}

Responses of the landslide slope to anthropogenic impacts were analyzed with taking into account nine-year-long observations over the vertical displacements of landslide points reliably fixed on its surface. The graphs on temporal changes of observed landslide displacements showed that the number of observation cycles and their deadlines are unable to reveal the seasonal impact of natural factors because of anthropogenic influences. At the same time, the impact of blasting operations and slope unloading led to unambiguous coherent changes of negative and positive displacement values, confirmed by geodetic observations over the displacement parameters and their speed. Mathematical modeling of the development of negative and positive displacements was carried out separately, which enabled to find regularities in slope response to two types of anthropogenic impacts. The dynamic modeling was based on the analyzed process distribution law, approximated over time by trend component, standard, and auto-correlation function, which allowed assessing expected landslide dynamics under different conditions.

Within the study, the following input impacts were used to build up prediction mathematical models:

$Z_{k}$ - change in charge mass when carrying out blasting operations throughout the entire cycle of geodetic observations; $V_{k^{-}}$change in the volume of removed soil after blasting operations throughout all cycles of geodetic observations.

As output factor $x_{k}$, the displacement values of landslide points at $k^{\text {th }}$ sampling step were used (adjustment by Yu. Fedoseev).

The overall period for prediction models was 9 years; the observation sampling interval was equal to 0.2 years. 
Below is a group of prediction mathematical models with two input impacts $x\left(Z_{k}, V_{k}\right)$ observed every 0.2 year for each landslide point $(8021,8022,8023,8024,8025)$ :

Landslide point 8021

$$
\begin{aligned}
& \hat{x}_{k / k-1}=0.9985 x_{k-1}-0.3583 x_{k-2}+2.3672 Z_{k}-1.9248 V_{k}+0.3196+0.5511 \omega_{k} ; \\
& \omega_{k}=1.1676 \omega_{k-1}-0.2207 \omega_{k-2} .
\end{aligned}
$$

Landslide point 8022

$$
\begin{aligned}
& \hat{x}_{k / k-1}=0.9906 x_{k-1}-0.4340 x_{k-2}+1.6273 Z_{k}-1.5672 V_{k}+0.4127+0.7389 \omega_{k} ; \\
& \omega_{k}=1.0388 \omega_{k-1}-0.1499 \omega_{k-2} .
\end{aligned}
$$

Landslide point 8023

$$
\begin{aligned}
& \hat{x}_{k / k-1}=1.1064 x_{k-1}-0.5172 x_{k-2}+1.4879 Z_{k}-1.0839 V_{k}-0.0502+0.9069 \omega_{k} ; \\
& \omega_{k}=0.4165 \omega_{k-1}-0.2406 \omega_{k-2} .
\end{aligned}
$$

Landslide point 8024

$$
\begin{aligned}
& \hat{x}_{k / k-1}=0.9974 x_{k-1}-0.3144 x_{k-2}-0.8206 Z_{k}+0.6765 V_{k}-0.1974+0.3224 \omega_{k} \\
& \omega_{k}=1.2926 \omega_{k-1}-0.3480 \omega_{k-2} .
\end{aligned}
$$

Landslide point 8025

$$
\begin{aligned}
& \hat{x}_{k / k-1}=0.9928 x_{k-1}-0.4427 x_{k-2}-4.9242 Z_{k}+4.2044 V_{k}-0.5048+1.7062 \omega_{k} ; \\
& \omega_{k}=0.9824 \omega_{k-1}-0.1629 \omega_{k-2} .
\end{aligned}
$$

Tab. 1 gives the values of root-mean-square errors $m$, calculated upon discrepancies between adjusted and approximated displacements of landslide points.

Table 1. Forecasting root-mean-square errors

\begin{tabular}{l|c|c|c|ccc}
\hline Landslide point number & 8021 & 8022 & 8023 & 8024 & 8025 \\
\hline$m, \mathrm{~mm}$ & 0.43 & 0.37 & 0.68 & 0.37 & 0.53 \\
\hline
\end{tabular}

\subsection{Use of the results of mathematical modeling in a spatial knowledge-based system}

Presently, the development of economic and financial situation depends on the use of geospatial data. One of the main goals of infrastructural organization of geospatial data is to provide users to be capable of acquiring complete, exact and updated dataset at the right time. With the advance of information technology, the capabilities of data storage, data mining, and data productivity have triggered a rise in the use of spatial information, especially in the area of regional social and economic development, management and safety (Ahsan et al. 2016; Chan et al., 2018). Efficient decision making at the level of regional or interregional spatial development and management relies on the collected information (format, source, attributes etc.) and the knowledge of decision makers. To assist the decision makers in using, selecting, and processing in- 
formation, spatial knowledge base and knowledge-based systems are developed (Harmon and King 1985; Cockcroft 2004). Fig. 10 represents an example of key elements of a knowledge-based system and their interdependency that enable to optimize workflows and provide safety and sustainability of an economically important link of a production chain (LPC), which may be unique, especially in such regions as Siberia and the Far East, supporting the operation of a number of production chains and industries. Frank et al. (2007) note that the keystone elements of the system are to be regularly updated with spatial data (observations), which are used in decision-making and management. Mathematical models describing, simulating, and predicting the LPC state, its significant facilities and their environment, and "solvers" that automatically trigger alerts, lists and protocols of needed actions and warnings when something may get or is getting out of control, either endangers operation of the LPC, allow specialists and decision makers to undertake preventive actions to keep it in accident-free operation.

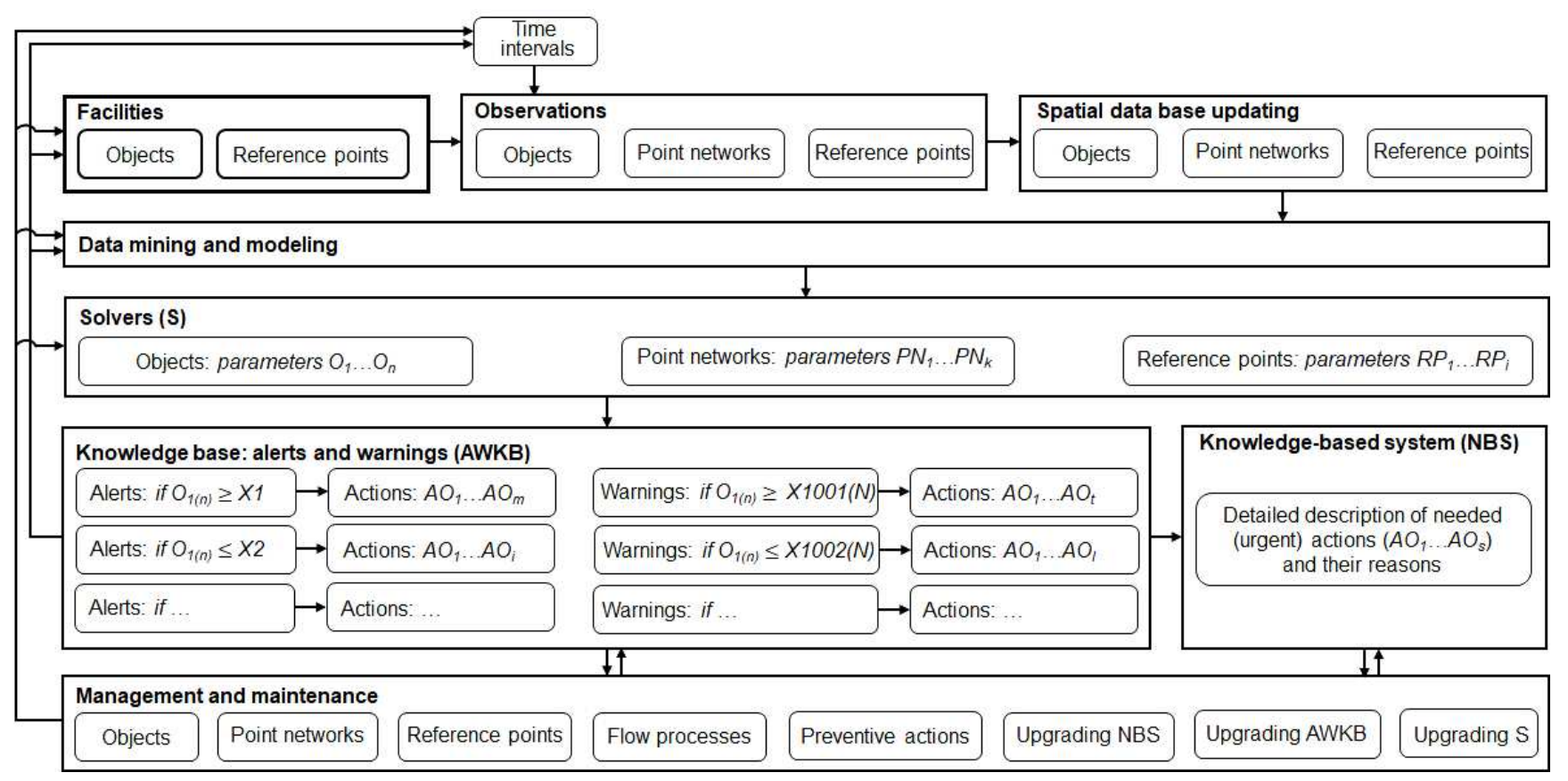

Figure 10. Keystone elements of a spatial knowledge-based system

Presently there is a number of methods for knowledge representation based on different mathematical models (Hatzilygeroudis and Prentzas 2004; Brachman and Levesque 2004; Wang 2011; Do et al. 2013; Nguyen et al. 2018; Wang and Zatarain 2018; Zhai et al. 2018; Krótkiewicz 2018; Aditya et al. 2019; Nguyen et al. 2020). In our case, the Rela-Ops model offered by Nguyen et al. (2020) seems to be most appropriate for combining all kinds of spatial data into knowledge. The model is based on not only object-oriented approaches but also ontology, and includes foundation components consisting of concepts, relations, operators, and inference rules. Besides the structure, each concept of this model is a class of objects, which solve problems on their own. Its processing of algorithms for solving problems combines the knowledge of relations and operators in the reasoning. What is more a knowledge model for multiple knowledge domains, in which each sub- 
domain has the form as the Rela-Ops model, may be built increasing ability and efficiency of the automated monitoring and maintaining of a complicated network of dependent LPCs.

During the study, modified Rela-Ops model and its algorithms were tested on the experimental data, which proved their validity for building reliable intelligent spatial problem solvers providing from 95.2 to $96.4 \%$ of correct management decisions.

\section{Discussion}

Analyzing the spectrograms (Fig. 2 a, b) of vertical displacements of the two groups of landslide points, two main harmonics with frequencies 40 and 75 were identified that match the periods of 12 and 3 months. The spectrograms of influencing factors enabled to find out bursts at frequency 40 that is associated with natural impacts and matches the period of 12 months. It is obvious, that this harmonics is caused by seasonal fluctuations. The spectrogram of vertical displacements of the first group of landslide points demonstrates a sharp peak in the vicinity of zero frequency (Fig. 2 a) and intensive low-frequency fluctuations. When restoring this part of the spectrum, a straight line with a slight time axis inclination was obtained, which can be interpreted as the development of vertical displacements of landslide points.

The spectrogram of the second group of landslide points (Fig. 2 b) has a gentler peak in the area of zero frequency and more intensive low-frequency fluctuations. When restoring this part of the spectrum, a straight line with a more significant time axis inclination was obtained, which means that the speed of vertical displacements of the second group of landslide points is higher than the first one.

The spectrograms on changing the amount of soil taken out during slope unloading and changing the charge value in the course of blasting operations (Fig. 3 b) show a peak in the area of frequency 75 that matches the period of 8 months, and that both spectrograms are practically identical. The same frequency was observed in the spectrograms of vertical displacements of landslide points, which makes it possible to conclude that blasting operations and slope unloading are the major influencing factors responsible for vertical displacements of landslide points. It should be noted that apart from the main seasonal frequency 40, the spectrogram of changes in the Angara water level also has a peak at frequency 75 , which means that blasting operations influence the changes in the Angara water level (Fig. 4 b). This is additionally confirmed by the fact that spectrograms of other meteorological factors do not have peaks at this frequency.

Then the spectrograms of horizontal displacements of both groups of landslide points were analyzed. The obtained results demonstrated that they correlate with vertical displacements and are influenced by the same factors as in case of vertical displacements. The described periodicity of the influencing factors upon displacements of the analyzed landslide points was revealed across the whole area of the right-bank landslide slope.

To specify the periodicity of these impacts, we analyzed the nature of blasting operations and slope unloading impacts. To this purpose we identified time dependencies on changing the charge in the course of blasting operations; chang- 
ing the amount of removed soil in the course of slope unloading in the landslide area; changing the amount of bulk soil in the area of rocky earth deposits. These areas were chosen because landslide slope unloading and filling in rocky earth deposits took place in the close vicinity to the landslide points used for geodetic observations (8061-8063) and the fact that these observations were carried out for 9 years. The analysis of the above processes showed that earth works on the slope unloading were carried out every two-three years with following decrease of their intensity, which gave a broader and fuller picture of the processes in the site.

The heights of all landslide points in the analyzed group were adjusted according to the method offered by $\mathrm{Yu}$. Fedoseev, i.e., estimates of their actual heights were obtained by separate modeling of negative and positive displacement trends reflecting the response of the landslide slope to blasts and unloading (Fig. 5). It was found that in 21 of 120 cases, the speed values exceed their calculation errors significantly. The closeness of the speed values and their errors is due to low speeds that take place at short inter-cycle time intervals and insufficient accuracy of geodetic observations (III class leveling).

It should be taken into account that estimated values of positive speeds were slightly reduced because of landslide slope unloading during its natural downward sliding, while negative speeds decreased under the inertial impact of the preceding unloading. Thus, different response of landslide slope to blasting and unloading impacts was proven. Later this formed the grounds for considering negative and positive components of vertical displacement process separately according to their deterministic and probabilistic nature. The above process components were centered separately, which revealed the nature of the two types of anthropogenic impacts as temporal changes of average displacement values, registered with geodetic observations. The centered values of the negative component of the process had, mainly, a positive development trend, while the positive component showed a negative development trend, confirming the above-described compensatory and inertial impact of the influencing factors.

The centered values of both components of the process mainly reflect natural character of its development and are slightly prone to anthropogenic impacts. Therefore, they were close to each other, which allowed us to combine them by averaging on closely adjacent sections, including centered values of some remote sections. Five integrated implementations of the centered process were obtained as well as graphs of the development of average negative and positive vertical displacements characterizing the degree of influence of each of the considered anthropogenic impacts.

As a result of the studies carried out, analytical validation and experimental assessment of the technique describing the process of landslide slope movement represented by two separate components related to blasting operations and slope unloading due to removal of soil from rock quarries was done. The technique of transition to centered normally distributed process of vertical landslide displacements with zero mathematical expectation, independent from blasting and unloading 
impacts, and the procedure of landslide process dynamic modeling with inverse verification of reference and model values of centered displacements were also developed.

At the final stage, dynamic mathematical modeling was carried out according to recurrent expression (1). The modeling matches the physical essence of the process development by taking into account the inertial nature of displacements monitored by geodetic observations as well as influencing factors and their temporal changes. To describe the dynamics of the analyzed process, we used an "input-output" second-order inertia model, representing the displacement of a randomly selected landslide point under the influence of two main anthropogenic factors.

Dynamic mathematical modeling of a landslide processes (prediction models) was used in algorithms forming a "solver" (intelligent problems solver) of a spatial expert system and later tested with a spatial knowledge base of a modified Rela-Ops model. Managing decisions made by the spatial knowledge base of the modified Rela-Ops model over 251 situations simulated for 5 spatial classes proved to be highly efficient showing their reliability in 239 cases.

\section{Conclusions}

Summarizing the results of the studies on dynamic mathematical modeling of landslide processes and the use of the built prediction models as an intelligent problem solver of a spatial expert system, we shall underline the following:

- detailed representation and analysis of spatial information depends on the location and density of landslide reference points and time frame of geodetic observations over their displacements;

- to carry out credible and high-quality mathematical modeling it is necessary to have complete quantitative data on the development of major factors influencing landslide activity, and zones of their influence;

- partial loss and sparseness of landslide reference points hampered reconstruction of an unbiased spatiotemporal picture of landslide movements, because of that we cannot clime the completeness and detail analysis of the studied processes;

- correlation of vertical and horizontal displacements confirms the overall landslide behavior revealed by geodetic observations; the analysis showed regularities of the impact of influencing factors upon the displacements, which enabled to describe them at a new level;

- correct selection of the input influencing factors and the type of a mathematical model allowed using built-up mathematical models to forecast the future displacements of observed landslide points when studying the landslide slope dynamics; the forecast RMSE for the displacement of different landslide points varied from 0.37 to $0.68 \mathrm{~mm}$, which indicates the high accuracy of the forecast;

- presented technique for identifying features and regularities of landslide behavior was used as an intelligent problems solver of a spatial expert system, based on the modified Rela-Op model under conditions of incomplete information. Verification of the methodology on simulated situations showed that it can be efficiently used as a "solver" of a 
spatial expert system when dealing with similar and other types of slope impacts supported by sufficient geodetic observations.

\section{References}

Aditya S, Yang Y, Baral C (2019) Integrating Knowledge and Reasoning in Image Understanding. https://doi.org/10.24963/ijcai.2019/873

Ahsan R, Neamtu R, Rundensteiner E (2016) Using Entity Identification and Classification for Automated Integration of Spatial-Temporal Data. Int J Des Nat Ecodyn 11 (3):186-197. https://doi.org/10.2495/DNE-V11-N3-186-197

Akgun A, Sezer EA, Nefeslioglu HA, Gokceoglu C, Pradhan B (2012) An Easy-to-use MATLAB Program (MamLand) for the Assessment of Landslide Susceptibility using a Mamdani Fuzzy Algorithm. Comput Geosci 38 (1):23-34. https://doi.org/10.1016/j.cageo.2011.04.012

Ali S, Biermanns P, Haider R, Reicherter K (2019) Landslide Susceptibility Mapping by using a Geographic Information System (GIS) Along the China-Pakistan Economic Corridor (Karakoram Highway), Pakistan. Nat Hazard Earth Sys 19 (5):999-1022. https://doi.org/10.5194/nhess-19-999-2019

Allstadt K (2013) Extracting Source Characteristics and Dynamics of the August 2010 Mount Meager Landslide from Broadband Seismograms. J Geophys Res: Earth Surface 118 (3): 1472-1490. https://doi.org/10.1002/jgrf.20110

Atif I., Ashraf H, Cawood FT, Mahboob MA (2021) A Conceptual Digital Framework for Near Real-Time Monitoring and Management of Mine Tailing Storage Facilities. Vol. 109. https://doi.org/10.1007/978-3-030-60839-2_27

Baborykin MYu, Zhirdilyaeva EV (2014) Landslide monitoring using laser scanning and geodetic observations. Eng Surv 3: 16-24 [Russian]

Baborykin MYu, Zhirdilyaeva EV, Pogosyan AG (2015) Revealing hazardous geological processes for engineeringgeoogical survey on the basis of digital terrain models. Eng Surv 2:30-36 [Russian]

Bai X, Jian J, He S, Liu W (2019) Dynamic Process of the Massive Xinmo Landslide, Sichuan (China), from Joint Seismic Signal and Morphodynamic Analysis. B Eng Geol Environ 78 (5):3269-3279. https://doi.org/10.1007/s10064-018$1360-0$

Bell S, Morse S (2018) Sustainability Indicators Past and Present: What Next? Sustainability (Switzerland) 10 (5). https://doi.org/10.3390/su10051688

Bermúdez JD, Corberán-Vallet A, Vercher E (2009) Multivariate Exponential Smoothing: A Bayesian Forecast Approach Based on Simulation. Math Comput Simul 79 (5):1761-1769. https://doi.org/10.1016/j.matcom.2008.09.004

Boogar AR, Salehi H, Pourghasemi HR, Blaschke T (2019) Predicting Habitat Suitability and Conserving Juniperus Spp. Habitat using SVM and Maximum Entropy Machine Learning Techniques. Water 11 (10). https://doi.org/10.3390/w11102049 
Box GEP, Jenkins G, Reinsel GC, Ljung GM (2015) Time Series Analysis. Forecasting and Control. Hoboken, New Jersey Brachman RJ, Levesque HJ (2004) Knowledge Representation and Reasoning. San Francisco, CA

Bui D, Pradhan B, Lofman O, Revhaug I, Dick OB (2012) Landslide Susceptibility Assessment in the Hoa Binh Province of Vietnam: A Comparison of the Levenberg-Marquardt and Bayesian Regularized Neural Networks. Geomorphology 171-172:12-29. https://doi.org/10.1016/j.geomorph.2012.04.023

Bui D, Tuan TA, Klempe H, Pradhan B, Revhaug I (2016) Spatial Prediction Models for Shallow Landslide Hazards: A Comparative Assessment of the Efficacy of Support Vector Machines, Artificial Neural Networks, Kernel Logistic Regression, and Logistic Model Tree. Landslides 13 (2):361-378. https://doi.org/10.1007/s10346-015-0557-6

Carter W, Shrestha R, Tuell G, Bloomquist D, Sartori M (2001) Airborne Laser Swath Mapping Shines New Light on Earth's Topography. Eos 82 (46). https://doi.org/10.1029/01EO00321

Chan H-Y, Yang C-H, Tsai M-H, Kang S-C (2018) Knowledge Base for a Disaster Management Dialogue System

Chen L-H, Chen C-T, Pan Y-G (2010) Groundwater Level Prediction using SOM-RBFN Multisite Model. J Hydrol Eng 15 (8):624-631. https://doi.org/10.1061/(ASCE)HE.1943-5584.0000218

Cignetti M, Godone D, Wrzesniak A, Giordan D (2019) Structure from Motion Multisource Application for Landslide Characterization and Monitoring: The Champlas Du Col Case Study, Sestriere, North-Western Italy. Sensors (Switzerland) 19 (10). https://doi.org/10.3390/s19102364

Cockcroft S (2004) The Design and Implementation of a Repository for the Management of Spatial Data Integrity Constraints. GeoInform. 8 (1):49-69. https://doi.org/10.1023/B:GEIN.0000007724.37467.ae

Dammeier F, Moore JR, Hammer C, Haslinger F, Loew S (2016) Automatic Detection of Alpine Rockslides in Continuous Seismic Data using Hidden Markov Models. J Geophys Res-Earth 121 (2):351-371. https://doi.org/10.1002/2015JF003647

Dammeier F, Moore JR, Haslinger F, Loew S (2011) Characterization of Alpine Rockslides using Statistical Analysis of Seismic Signals. J Geophys Res-Earth 116 (4). https://doi.org/10.1029/2011JF002037

Diao XD, Zeng SX, Tam CM, Tam VWY (2009) EKC Analysis for Studying Economic Growth and Environmental Quality: A Case Study in China. J Clean Prod 17 (5):541-548. https://doi.org/10.1016/j.jclepro.2008.09.007

Do HM, Yin KL, Guo ZZ (2020) A Comparative Study on the Integrative Ability of the Analytical Hierarchy Process, Weights of Evidence and Logistic Regression Methods with the Flow-R Model for Landslide Susceptibility Assessment. Geomat Nat Haz Risk 11 (1): 2449-2485. https://doi.org/10.1080/19475705.2020.1846086

Do NV, Nguyen HD, Mai TT (2013) Designing an Intelligent Problems Solving System Based on Knowledge about Sample Problems. Lecture Notes in Computer Science (Including Subseries Lecture Notes in Artificial Intelligence and Lecture Notes in Bioinformatics). Vol. 7802 LNAI. https://doi.org/10.1007/978-3-642-36546-1_48 
Dong M, Hu H, Song J (2018) Combined Methodology for Three-Dimensional Slope Stability Analysis Coupled with Time Effect: A Case Study in Germany. Environ Earth Sci 77 (8). https://doi.org/10.1007/s12665-018-7497-0

Dong M, Wu H, Hu H, Azzam R, Zhang L, Zheng Z, Gong X (2021) Deformation Prediction of Unstable Slopes Based on Real-Time Monitoring and Deepar Model. Sensors-Basel 21 (1): 1-18. https://doi.org/10.3390/s21010014

Dou J, Yunus AP, Bui DT, Merghadi A, Sahana M, Zhu Z, Chen C-W, Han Z, Pham BT (2020) Improved Landslide Assessment using Support Vector Machine with Bagging, Boosting, and Stacking Ensemble Machine Learning Framework in a Mountainous Watershed, Japan. Landslides 17 (3): 641-658. https://doi.org/10.1007/s10346-019-01286-5

Duan G, Chen D, Niu R (2019) Forecasting Groundwater Level for Soil Landslide Based on a Dynamic Model and Landslide Evolution Pattern. Water-Sui 11 (10). https://doi.org/10.3390/w11102163

Dunning SA, Massey CI, Rosser NJ (2009) Structural and Geomorphological Features of Landslides in the Bhutan Himalaya Derived from Terrestrial Laser Scanning. Geomorphology 103 (1):17-29. https://doi.org/10.1016/j.geomorph.2008.04.013

Federici PR, Puccinelli A, Cantarelli E, Casarosa N, D'Amato Avanzi G, Falaschi F, Giannecchini R, et al (2007) Multidisciplinary Investigations in Evaluating Landslide Susceptibility-an Example in the Serchio River Valley (Italy). Quat Int 171-172 (SPEC. ISS.):52-63. https://doi.org/10.1016/j.quaint.2006.10.018

Feng Z-Y, Lo C-M, Lin Q-F (2017) The Characteristics of the Seismic Signals Induced by Landslides using a Coupling of Discrete Element and Finite Difference Methods. Landslides 14 (2):661-674. https://doi.org/10.1007/s10346-016-07146

Frank A, Krieger H-U, Xu F, Uszkoreit H, Crysmann B, Jörg B, Schäfer U (2007 Question Answering from Structured Knowledge Sources. J Appl Logic 5 (1):20-48. https://doi.org/10.1016/j.jal.2005.12.006

Fuchs F, Lenhardt W, Bokelmann G (2018) Seismic Detection of Rockslides at Regional Scale: Examples from the Eastern Alps and Feasibility of Kurtosis-Based Event Location. Earth Surf Dyn 6 (4):955-970. https://doi.org/10.5194/esurf-6$955-2018$

Gayen A, Pourghasemi HR, Saha S, Keesstra S, Bai S (2019) Gully Erosion Susceptibility Assessment and Management of Hazard-Prone Areas in India using Different Machine Learning Algorithms. Sci Total Environ 668:124-138. https://doi.org/10.1016/j.scitotenv.2019.02.436

Godone D, Giordan D, Baldo M (2018) Rapid Mapping Application of Vegetated Terraces Based on High Resolution Airborne Lidar. Geomat Nat Haz Risk 9 (1):970-985. https://doi.org/10.1080/19475705.2018.1478893

Greco R, Sorriso-Valvo M, Catalano E (2007) Logistic Regression Analysis in the Evaluation of Mass Movements Susceptibility: The Aspromonte Case Study, Calabria, Italy. Eng Geol 89 (1-2):47-66. https://doi.org/10.1016/j.enggeo.2006.09.006 
Guinau M, Tapia M, Pérez-Guillén C, Suriñach E, Roig P, Khazaradze G, Torné M, Royán MJ, Echeverria A (2019) Remote Sensing and Seismic Data Integration for the Characterization of a Rock Slide and an Artificially Triggered Rock Fall. Eng Geol 257. https://doi.org/10.1016/j.enggeo.2019.04.010

Gundogdu KS, Guney I (2007) Spatial Analyses of Groundwater Levels using Universal Kriging. J Earth Syst Sci 116 (1): 49-55. https://doi.org/10.1007/s12040-007-0006-6

Guo J, Yi S, Yin Y, Cui Y, Qin M, Li T, Wang C (2020) The Effect of Topography on Landslide Kinematics: A Case Study of the Jichang Town Landslide in Guizhou, China. Landslides 17 (4):959-973. https://doi.org/10.1007/s10346019-01339-9

Han Z, Jiao S, Zhang X, Xie F, Ran J, Jin R, Xu S (2021) Seeking Sustainable Development Policies at the Municipal Level Based on the Triad of City, Economy and Environment: Evidence from Hunan Province, China. J Environ Manage 290. https://doi.org/10.1016/j.jenvman.2021.112554

Harmon P, King D (1985) Expert Systems: Artificial Intelligence in Business. Technol Cult 28:894

Hatzilygeroudis L, Prentzas J (2004) Knowledge Representation Requirements for Intelligent Tutoring Systems. Lecture Notes in Computer Science (Including Subseries Lecture Notes in Artificial Intelligence and Lecture Notes in Bioinformatics). Vol. 3220. https://doi.org/10.1007/978-3-540-30139-4_9

Hong H, Pradhan B, Xu C, Tien Bui D (2015) Spatial Prediction of Landslide Hazard at the Yihuang Area (China) using Two-Class Kernel Logistic Regression, Alternating Decision Tree and Support Vector Machines. Catena 133:266-281. https://doi.org/10.1016/j.catena.2015.05.019

Hosseinalizadeh, M, Kariminejad N, Chen W, Pourghasemi HR, Alinejad M, Mohammadian Behbahani A, Tiefenbacher JP (2019) Spatial Modelling of Gully Headcuts using UAV Data and Four Best-First Decision Classifier Ensembles (BFTree, Bag-BFTree, RS-BFTree, and RF-BFTree). Geomorphology 329:184-193. https://doi.org/10.1016/j.geomorph.2019.01.006

Hsu Y-C, Chang Y-L, Chang C-H, Yang J-C, Tung Y-K (2018) Physical-based rainfall-triggered shallow landslide forecasting. Smart Water 3, 3. https://doi.org/10.1186/s40713-018-0011-8

Hu S, Qiu H, Pei Y, Cui Y, Xie W, Wang X, Yang D, et al (2019) Digital Terrain Analysis of a Landslide on the Loess Tableland using High-Resolution Topography Data. Landslides 16 (3):617-632. https://doi.org/10.1007/s10346-0181103-0

Huang F-M, Yin K, He T, Zhou C, Zhang J (2016) Influencing Factor Analysis and Displacement Prediction in Reservoir Landslides - A Case Study of Three Gorges Reservoir (China). Teh Vjesn 23 (2):617-626. https://doi.org/10.17559/TV20150314105216 
Huang F, Yao C, Liu W, Li Y, Liu X (2018) Landslide Susceptibility Assessment in the Nantian Area of China: A Comparison of Frequency Ratio Model and Support Vector Machine. Geomat Nat Haz Risk 9 (1):919-938. https://doi.org/10.1080/19475705.2018.1482963

Huang F, Huang J, Jiang S, Zhou C (2017) Landslide Displacement Prediction Based on Multivariate Chaotic Model and Extreme Learning Machine. Eng Geol 218:173-186. https://doi.org/10.1016/j.enggeo.2017.01.016

Hungr O, Leroueil S, Picarelli L (2014) The Varnes Classification of Landslide Types, an Update. Landslides 11 (2):167194. https://doi.org/10.1007/s10346-013-0436-y

Iverson RM (2000) Landslide Triggering by Rain Infiltration. Water Resour Res 36 (7):1897-1910. https://doi.org/10.1029/2000WR900090.

Jaboyedoff M, Oppikofer T, Abellán A, Derron M-H, Loye A, Metzger R, Pedrazzini A (2012) Use of LIDAR in Landslide Investigations: A Review. NAT HAZARDS 61 (1):5-28. https://doi.org/10.1007/s11069-010-9634-2

Jenkins GM, Watts D. G (1969) Spectral analysis and its applications. San Francisco, Holden-Day

Jia GW, Zhan TLT, Chen YM, Fredlund DG (2009) Performance of a Large-Scale Slope Model Subjected to Rising and Lowering Water Levels. Eng Geol 106 (1-2):92-103. https://doi.org/10.1016/j.enggeo.2009.03.003

Khoroshilov VS (2018) Mathematical Modelling of Sayano-Shushenskaya Dam Displacement Process After 2009 Accident. Int J Eng Res Africa 39:47-59. https://doi.org/10.4028/www.scientific.net/JERA.39.47

Khoroshilov V, Pavlovskaya O, Noskov M (2013) Analysis and estimation of landslide dynamics by the results of geodetic observations during firing and slope unloading. Izvestia Vuzov. Geodesy and Aerophotography 4:19-24 [Russian]

Klyushin EB, Mikhelev DS, Barkov DP (1993) Training Workshop on Applied Geodesy. Geodetic support of construction and operation of engineering facilities. Nedra, Moscow [Russian]

Kozhogulov KC, Nifadyev VI, Usmanov SF (2017) Prediction of slope stability based on numerical modeling of stressstrain state of rocks. J Fundam Appl Min Sci 4(3):54-59 [Russian]

Krótkiewicz M (2018) A Novel Inheritance Mechanism for Modeling Knowledge Representation Systems. Comput Sci Inf Syst 15 (1):51-78. https://doi.org/10.2298/CSIS170630046K

Kuzin AA, Sannikova AP (2016) Estimation method of landslide hazard developing territories based on GIS using geodetic data. Geodesy and Cartography 4:43-50 [Russian]

Lin C-H (2015) Insight into Landslide Kinematics from a Broadband Seismic Network Seismology. Earth Planets Space 67 (1). https://doi.org/10.1186/s40623-014-0177-8

Liu SY, Shao LT, Li HJ (2015) Slope Stability Analysis using the Limit Equilibrium Method and Two Finite Element Methods. Comput Geotech 63:291-298. https://doi.org/10.1016/j.compgeo.2014.10.008 
Manconi A, Picozzi M, Coviello V, De Santis F, Elia L (2016) Real-Time Detection, Location, and Characterization of Rockslides using Broadband Regional Seismic Networks. Geophys Res Lett 43 (13):6960-6967. https://doi.org/10.1002/2016GL069572

Mantovani M, Devoto S, Forte E, Mocnik A, Pasuto A, Piacentini D, Soldati M (2013) A Multidisciplinary Approach for Rock Spreading and Block Sliding Investigation in the North-Western Coast of Malta. Landslides 10 (5):611-622. https://doi.org/10.1007/s10346-012-0347-3

Mazzanti P, Schilirò L, Martino S, Antonielli B, Brizi E, Brunetti A, Margottini C, Mugnozza GS (2018) The Contribution of Terrestrial Laser Scanning to the Analysis of Cliff Slope Stability in Sugano (Central Italy). Remote Sens (Basel) 10 (9). https://doi.org/10.3390/rs10091475

Mohanty S, Jha MK, Kumar A, Sudheer KP (2010) Artificial Neural Network Modeling for Groundwater Level Forecasting in a River Island of Eastern India. Water Resour Manag 24 (9):1845-1865. https://doi.org/10.1007/s11269-0099527-X

Moretti L, Allstadt K, Mangeney A, Capdeville Y, Stutzmann E, Bouchut F (2015) Numerical Modeling of the Mount Meager Landslide Constrained by its Force History Derived from Seismic Data. J Geophys Res: Solid Earth 120 (4):2579-2599. https://doi.org/10.1002/2014JB011426

Nemirovich-Danchenko MM (2002) Numerical simulation of three-dimensional seismology problems. Phys Mesomech 5(5):59-66 [Russian]

Nguyen HD, Do NV, Tran NP, Pha XH (2018) Criteria of a Knowledge Model for an Intelligent Problems Solver in Education. https://doi.org/10.1109/KSE.2018.8573434

Nguyen HD, Do NV, Pham VT, Selamat A, Herrera-Viedma E (2020) A Method for Knowledge Representation to Design Intelligent Problems Solver in Mathematics Based on Rela-Ops Model. IEEE Access 8:76991-77012. https://doi.org/10.1109/ACCESS.2020.2988929

Ovsiuchenko NI, Akopov DN (2012) Laser scanning and monitoring of landslide slopes. Eng Surv 2:40-45 [Russian]

Pavlovskaya O, Khoroshilov V, Noskov M (2012) Method of identifying homogeneous landslide zones with geodetic survey of vertical movements of settling benchmarks. Izvestia Vuzov. Geodesy and Aerophotography 5:31-34 [Russian]

Pourghasemi HR, Rossi M (2017) Landslide Susceptibility Modeling in a Landslide Prone Area in Mazandarn Province, North of Iran: A Comparison between GLM, GAM, MARS, and M-AHP Methods. Theor Appl Climatol 130 (1-2):609633. https://doi.org/10.1007/s00704-016-1919-2

Pourghasemi HR, Sadhasivam N, Kariminejad N, Collins AL (2020) Gully Erosion Spatial Modelling: Role of Machine Learning Algorithms in Selection of the Best Controlling Factors and Modelling Process. Geosci Front 11 (6):22072219. https://doi.org/10.1016/j.gsf.2020.03.005 
Pradhan B (2013) A Comparative Study on the Predictive Ability of the Decision Tree, Support Vector Machine and Neuro-Fuzzy Models in Landslide Susceptibility Mapping using GIS. Comput Geosci 51:350-365. https://doi.org/10.1016/j.cageo.2012.08.023

Rowlands KA, Jones LD, Whitworth M (2003) Landslide Laser Scanning: A New Look at an Old Problem. Q J Eng Geol Hydroge 36 (2):155-157. https://doi.org/10.1144/1470-9236/2003-08

Sari PTK, Putri YE, Savitri YR, Amalia AR, Margini NF, Nusantara DAD (2020) The Comparison between 2-D and 3-D Slope Stability Analysis Based on Reinforcement Requirements. Int J Adv Sci Eng Inf Technol 10 (5):2082-2088. https://doi.org/10.18517/ijaseit.10.5.12815

Schuster RL, Krizek RJ (1978) Landslides. Analysis and control. National Academy of Sciences, Washington

Shan J, Toth K (2018) Topographic laser ranging and scanning: principles and processing. CRC Press

Simonyan VV (2011) Study of landslide processes by geodetic methods. Moscow State University of Civil Engineering, Moscow

Sun G, Zheng H, Tang H, Dai F (2016) Huangtupo Landslide Stability Under Water Level Fluctuations of the Three Gorges Reservoir. Landslides 13 (5):1167-1179. https://doi.org/10.1007/s10346-015-0637-7

Van Den Eeckhaut M, Hervás J, Jaedicke C, Malet J-P, Montanarella L, Nadim F (2012) Statistical Modelling of EuropeWide Landslide Susceptibility using Limited Landslide Inventory Data. Landslides 9 (3):357-369. https://doi.org/10.1007/s10346-011-0299-z

Walter M, Schwaderer U, Joswig M (2012) Seismic Monitoring of Precursory Fracture Signals from a Destructive Rockfall in the Vorarlberg Alps, Austria. Nat Hazard Earth Sys 12 (11):3545-3555. https://doi.org/10.5194/nhess-12-3545-2012

Wang H (2011) Research on the model of knowledge representation ontology based on framework in intelligent learning system. $6757-6760$

Wang L-J, Guo M, Sawada K, Lin J, Zhang J (2016) A Comparative Study of Landslide Susceptibility Maps using Logistic Regression, Frequency Ratio, Decision Tree, Weights of Evidence and Artificial Neural Network. Geosci J 20 (1):117136. https://doi.org/10.1007/s12303-015-0026-1

Wang Y, Zatarain OA (2018) Design and Implementation of a Knowledge Base for Machine Knowledge Learning. https://doi.org/10.1109/ICCI-CC.2018.8482034

Wen T, Tang H, Wang Y, Lin C, Xiong C (2017) Landslide Displacement Prediction using the GA-LSSVM Model and Time Series Analysis: A Case Study of Three Gorges Reservoir, China. Nat Hazard Earth Sys 17 (12):2181-2198. https://doi.org/10.5194/nhess-17-2181-2017 
Westoby MJ, Brasington J, Glasser NF, Hambrey MJ, Reynolds JM (2012) 'Structure-from-Motion' Photogrammetry: A Low-Cost, Effective Tool for Geoscience Applications. Geomorphology 179:300-314. https://doi.org/10.1016/j.geomorph.2012.08.021

Yamada M, Kumagai H, Matsushi Y, Matsuzawa T (2013) Dynamic Landslide Processes Revealed by Broadband Seismic Records. Geophys Res Lett 40 (12):2998-3002. https://doi.org/10.1002/grl.50437

Yan Y, Cui Y, Tian X, Hu S, Guo J, Wang Z, Yin S, Liao L (2020) Seismic Signal Recognition and Interpretation of the 2019 “7.23” Shuicheng Landslide by Seismogram Stations. Landslides 17 (5):1191-1206. https://doi.org/10.1007/s10346-020-01358-X

Yousefi S, Pourghasemi HR, Emami SN, Pouyan S, Eskandari S, Tiefenbacher JP (2020) A Machine Learning Framework for Multi-Hazards Modeling and Mapping in a Mountainous Area. Sci Rep 10 (1). https://doi.org/10.1038/s41598-020$69233-2$

Yousefi S, Khatami R, Mountrakis G, Mirzaee S, Pourghasemi HR, Tazeh M (2015) Accuracy Assessment of Land cover/land use Classifiers in Dry and Humid Areas of Iran. Environ Monit Assess 187 (10). https://doi.org/10.1007/s10661$015-4847-1$

Zeybek M, Şanlioğlu İ (2020) Investigation of Landslide Detection using Radial Basis Functions: A Case Study of the Taşkent Landslide, Turkey. Environ Monit Assess 192 (4). https://doi.org/10.1007/s10661-020-8101-0

Zhai Y, Li D, Zhang J (2018) Variable Decision Knowledge Representation: A Logical Description. J Comput Sci 25:161169. https://doi.org/10.1016/j.jocs.2017.03.019

Zhang R, Zhao J, Wang G (2016) Stability Analysis of Anchored Soil Slope Based on Finite Element Limit Equilibrium Method. Math Probl Eng 2016. https://doi.org/10.1155/2016/7857490 